\title{
Attribution of high resolution streamflow trends in Western Austria - an approach based on climate and discharge station data
}

\author{
C. Kormann ${ }^{1}$, T. Francke ${ }^{1}$, M. Renner ${ }^{2}$, and A. Bronstert ${ }^{1}$ \\ ${ }^{1}$ Institute of Earth and Environmental Science, University of Potsdam, Potsdam, Germany \\ ${ }^{2}$ Biospheric Theory and Modeling, Max Planck Institute for Biogeochemistry, Jena, Germany \\ Correspondence to: C. Kormann (ckormann@uni-potsdam.de)
}

Received: 6 June 2014 - Published in Hydrol. Earth Syst. Sci. Discuss.: 26 June 2014

Revised: 7 January 2015 - Accepted: 6 February 2015 - Published: 5 March 2015

\begin{abstract}
The results of streamflow trend studies are often characterized by mostly insignificant trends and inexplicable spatial patterns. In our study region, Western Austria, this applies especially for trends of annually averaged runoff. However, analysing the altitudinal aspect, we found that there is a trend gradient from higher-altitude to lower-altitude stations, i.e. a pattern of mostly positive annual trends at higher stations and negative ones at lower stations. At midaltitudes, the trends are mostly insignificant. Here we hypothesize that the streamflow trends are caused by the following two main processes: on the one hand, melting glaciers produce excess runoff at higher-altitude watersheds. On the other hand, rising temperatures potentially alter hydrological conditions in terms of less snowfall, higher infiltration, enhanced evapotranspiration, etc., which in turn results in decreasing streamflow trends at lower-altitude watersheds. However, these patterns are masked at mid-altitudes because the resulting positive and negative trends balance each other. To support these hypotheses, we attempted to attribute the detected trends to specific causes. For this purpose, we analysed trends of filtered daily streamflow data, as the causes for these changes might be restricted to a smaller temporal scale than the annual one. This allowed for the explicit determination of the exact days of year (DOYs) when certain streamflow trends emerge, which were then linked with the corresponding DOYs of the trends and characteristic dates of other observed variables, e.g. the average DOY when temperature crosses the freezing point in spring. Based on these analyses, an empirical statistical model was derived that was able to simulate daily streamflow trends sufficiently well. Analyses of subdaily streamflow changes provided additional insights. Finally, the present study supports many modelling
\end{abstract}

approaches in the literature which found out that the main drivers of alpine streamflow changes are increased glacial melt, earlier snowmelt and lower snow accumulation in wintertime.

\section{Introduction}

Climate change alters the hydrological conditions in many regions (Parry et al., 2007). Especially, watersheds in mountain regions are more sensitive than those in lowlands (Barnett et al., 2005; Viviroli et al., 2011). This is mostly due to the strong connection between mountain hydroclimatology and temperature increase, which is at least twice as strong in mountainous areas compared to the global average (Brunetti et al., 2009): on the one hand, increasing temperatures result in diminishing glaciers, earlier snowmelt and less precipitation falling in the form of snow; on the other hand, the local climate is changed by interdependencies such as the snowalbedo feedback (Hall et al., 2008).

A multitude of studies have tried to assess the detailed impacts of these changes through modelling approaches, especially for future scenarios (e.g. Magnusson et al., 2010; Tecklenburg et al., 2012; Vormoor et al., 2015). Another way of understanding climate change impacts on local hydrology is to analyse trends in observed streamflow data (e.g. Stahl et al., 2010; Dai et al., 2009). However, the aim of finding clear changing patterns is often hindered by strong noise in the data, as well as the fact that signals are usually small. Viviroli et al. (2011) note in their review paper on climate change and mountain water resources that trend studies in alpine regions often report "inconclusive or misleading findings". 
Other studies with different statistical approaches to analyse streamflow changes in alpine regions were published: in the mountainous areas of western North America, many studies agree that snowmelt and thus spring freshet is appearing earlier in the year (e.g. Stewart et al., 2005; Mote et al., 2005; Knowles et al., 2006). However, most of these studies are based on trends of indicators such as "centre of volume" or "day of occurrence of the annual peak flow", which serve as proxies to indicate consequences of global warming on alpine streamflow (i.e. earlier snowmelt). The application of these measures is problematic: Whitfield (2013) claims that the "centre of volume" is affected by other factors than temperature alone and has several shortcomings. Déry et al. (2009) found that these metrics should be avoided, because they are sensitive to factors such as record length, streamflow seasonality and data variability. Compared to these indicators, a measure that is based on a harmonic filter (Renner and Bernhofer, 2011) provides more robust estimates of the timing of the hydrological cycle. Other studies analysed temporally highly resolved trends (Kim and Jain, 2010; Déry et al., 2009; Kormann et al., 2014). These trends in daily resolution have the advantage that not only a shift in snowmelt timing but also other increases or decreases of the streamflow volume are revealed (Déry et al., 2009). Furthermore, a more detailed picture of the changes can be obtained by daily trends than by seasonal or annual averages, where a lot of the information is lost by averaging data over a certain period of time. In addition, the timing of daily trends (i.e. the day of year when a trend appears) reveals supplementary information on potential drivers of streamflow trends (Kormann et al., 2014).

In hydroclimatology, the proof that observed changes are significantly different from variations that could be explained by natural variability is referred to as trend detection, whereas trend attribution describes the assignment of these changes to specific causes. Kundzewicz (2004) underlines the importance of not only trend detection but also trend attribution to elucidate the reasons for these changes. In this context, it is common practice to set up comparisons or correlations between the variable under consideration and the features of the system in which it is embedded (Merz et al., 2012a). However, previous analyses often considered trend magnitudes as the main subject of investigation, e.g. the correlation of observed streamflow trend magnitudes with certain catchment characteristics (e.g. glacier coverage). In addition, trends used for correlation analyses were mainly derived from annual or seasonal (3-monthly) streamflow averages. Both of these approaches are only partially capable of attributing trends, as streamflow integrates multiple processes across the watershed and different time scales. Hence the isolation of trends that are caused by a single source is often not possible, resulting in ambiguous outcomes (Merz et al., 2012a). Additionally, correlation can only give hints and does not imply causation. This is especially true in our case, as many of the watershed attributes are themselves correlated with each other (usually, the higher a watershed, the more glaciated and the less vegetated it is). In recent years there has been some progress towards the attribution of streamflow trends via other approaches: Bard et al. (2011) made a relevant step forward by regime-specific trend analyses, as trend causing processes differ from one regime to another. Déry et al. (2009) used a simple model to simulate the cause-andeffect relations between the volume/timing of snowmelt and streamflow.

Apart from the hydrological changes caused by earlier spring snowmelt, it is often difficult to find robust links between trend causes and their effects in observational data. Few studies have analysed the long-term effects of glacier mass loss on streamflow. Glaciers may have already reached the turning point when glacier mass has decreased to such a degree that meltwater volumes are reduced as well (Braun et al., 2000). Stahl and Moore (2006) fitted a regression model for August streamflow and then analysed trends in the residuals. They found that most of the glacier-fed streams in British Columbia, Canada, are in the state of decreasing meltwater volumes. In Europe, however, Pellicciotti et al. (2010) related ice volume changes with streamflow trends and showed that streamflow is still increasing in four Swiss watersheds with high glacier coverage, and decreasing in one with low coverage.

Next to changes through earlier snowmelt and increased glacial melt, climate change also influences streamflow through e.g. increasing evapotranspiration (ET) (Walter et al., 2004) or an increase of the timber line (Walther, 2003). Nevertheless, robust links between detected trends and their causes are often missing.

Summing up, there are several studies that elaborate on certain aspects of trend causes in alpine catchments. However, an integrated attempt would be desirable. For this purpose, the present study combines the benefits of a temporally highly resolved trend analysis that is applicable to all alpine runoff regimes with hydrological process understanding to explain seasonal streamflow changes in Western Austria. We aim to extend the knowledge about regional trend causes, with an attempt to provide a holistic picture of the changes found under different alpine streamflow conditions. We limit our study to changes in mean values, and exclude analyses of extreme values since these changes might be caused by different processes. For publications on low flow and flood regime changes, see e.g. Birsan et al. (2005), Parajka et al. (2009, 2010), Blöschl et al. (2011) and Hall et al. (2014).

The present study is divided into two parts. On the basis of the findings in the first part (an analysis of annually averaged trends/indicators), we derived the following hypotheses:

- In higher-altitude, glaciated watersheds in the study region, rising temperatures result in increased glacial melt, which in turn causes positive annual streamflow trends. Most of the larger glaciers still have not reached 
the point where annual streamflow decreases because of decreasing glacier area.

- In lower-altitude, unglaciated watersheds, increasing temperatures result in earlier snowmelt and less precipitation falling as snow. This in turn leads to multiple hydrological changes such as higher ET, higher infiltration or changing storage characteristics, to name a few. The negative streamflow trends in the study region are a result of these changes.

- In watersheds located at middle altitudes and covered by a smaller glacier percentage, both processes are prevalent to a lesser degree and compensate for each other.

To support these theories, it is necessary to attribute the streamflow trends. This is done in the second part of the study: it is realized via a seasonal examination of the changes, as the driving processes for these changes might be limited to a smaller scale than the annual one.

\section{Data}

The study area is situated in Western Austria, mainly in North Tirol. With $970 \pm 290 \mathrm{~mm}$ average precipitation per year (based on station data, 1980-2010), this is a relatively dry region in the Alps as it is situated in the rain shadow of the northern and southern alpine border ranges. The study region includes altitudes from $673 \mathrm{~m}$ up to $3768 \mathrm{~m}$ a.s.l., with an extent of roughly $200 \mathrm{~km}$ in the east-west direction and $60 \mathrm{~km}$ in the north-south direction. There is a temperate climate with distinct precipitation maxima in summer. The majority of the watersheds under study drain into the Inn, Drava and Lech rivers, all tributaries of the Danube. For the most part, grassland and coniferous forest dominate the land use in the lower catchment areas, whereas the percentage of rocky areas with little or no vegetation increases with increasing watershed altitude. Due to the strong influence of glacier and snowmelt, mostly glacial and nival discharge regimes prevail, which means discharge quantities have a distinct seasonal cycle with maxima in spring or summer and low flows in winter.

In the present analysis, we studied daily observations of mean, minimum and maximum temperatures $\left(T_{\mathrm{avg}}: 29\right.$, $T_{\min }: 12$ and $T_{\max }: 10$ stations), snow depth (SD: 43 stations) and streamflow ( $Q: 32$ gauges), which were provided by Hydrographischer Dienst Tirol (Innsbruck), AlpS GmbH (Innsbruck), Zentralanstalt für Meteorologie und Geodynamik (Vienna) and Tiroler Wasserkraft AG (Innsbruck). $T_{\min }$ and $T_{\max }$ data was taken from the HOMSTART data set (homogenized station data sets, Nemec et al., 2012). Hourly temperature data were only available for the Vernagt station, and were provided by the Kommission für Glaziologie (Munich, Escher-Vetter et al., 2014). The IDs of the $T$ and SD stations were generated from the rank of station altitude, $Q$ station
IDs from the rank of mean watershed altitude; i.e. the higher the adjacent watershed, the lower the ID. Prior to the analysis, streamflow records were normalized by catchment area (flow rate per unit area). In Kormann et al. (2014), precipitation trends were studied as well. However, no clear and coherent significant change patterns could be identified in this study (similar to e.g. Pellicciotti et al., 2010 or Schimon et al., 2011). Precipitation changes might exist, but cannot be detected due to methodological limitations stemming from a low signal-to-noise ratio.

All hydroclimatic data sets were checked by Austrian government officials via extensive examinations and plausibility checks. We additionally ensured that no data inhomogeneities remained. We further excluded streamflow records of catchments influenced by major hydro-electric power production. Unfortunately, it was impossible to exclude all watersheds with influences from hydro power stations, as water resources in Western Austria are used extensively: in Tirol alone there are approximately 950 small-scale hydro power plants of differing type with a capacity lower than $10 \mathrm{MW}^{1}$. However, the great majority of the small hydro power plants in Austria are run-of-river power plants (A. Egger (Tirolean spokesman of the association of small hydro power plants in Austria), personal communication, 29 July 2014). These power plants do not have any pondage and thus there is no delay of river runoff. The rest of the small hydro power plants are mostly equipped with 1-day water storage volumes, which means there is a maximum delay of an average daily discharge amount, so the impacts on the seasonal discharge behaviour are very limited.

Nine of the 32 catchments analysed are nested. We used the approach that was applied as well in Birsan et al. (2005): to guarantee spatial independence of the station data, we checked for a considerable increase in watershed area among the corresponding gauges. Only the station pair Innergschlöß $\left(39 \mathrm{~km}^{2}\right)$ and Tauernhaus $\left(60 \mathrm{~km}^{2}\right)$ did not meet the requirements as defined in Birsan et al. (2005). However, as these basins were necessary to increase the number of catchments with glacial influence and the requirements of station independence were not violated too strongly, we left them in the data set.

We selected the period 1980-2010 for the data analysis. This ensured consistent data length for all hydroclimatic variables and best data availability. In this period, the Greater Alpine Region experienced a strong increase in air temperature by about $1.3^{\circ} \mathrm{C}$, compared to about $0.7^{\circ} \mathrm{C}$ between 1900 and 1980 (Auer et al., 2007). Furthermore, the magnitudes of streamflow, temperature, snow depth and snowfall trends are greatest for this period within the study region (Kormann et al., 2014).

The characteristics of the watersheds and their IDs are summarized in Table 1. Figure 1 shows a map of the study

\footnotetext{
${ }^{1}$ http://www.kleinwasserkraft.at/en/hydropower-tyrol, July 2014
} 
Table 1. List of the gauging stations used in this study (sorted by mean altitude) and their characteristics.

\begin{tabular}{|c|c|c|c|c|c|c|c|c|}
\hline $\begin{array}{l}\text { Station } \\
\text { ID }\end{array}$ & $\begin{array}{l}\text { Station name (and ID } \\
\text { of nested basin) }\end{array}$ & $\begin{array}{r}\text { Altitude } \\
(\mathrm{m})\end{array}$ & Latitude & Longitude & $\begin{array}{r}\text { Gauged } \\
\text { area } \\
\left(\mathrm{km}^{2}\right)\end{array}$ & $\begin{array}{c}\text { Mean } \\
\text { basin } \\
\text { altitude } \\
\text { (m) }\end{array}$ & $\begin{array}{r}\text { Glacier } \\
\text { coverage } \\
(\%)\end{array}$ & $\begin{array}{l}\text { Maximum } \\
\text { basin } \\
\text { altitude } \\
\text { (m) }\end{array}$ \\
\hline 1 & Vernagt & 2640 & 46.8678 & 10.8007 & 11 & 3127 & 71.9 & 3535 \\
\hline 2 & Vent (1) & 1891 & 46.8665 & 10.8895 & 90 & 2934 & 33.0 & 3768 \\
\hline 3 & Gepatschalm & 1895 & 46.9112 & 10.7142 & 55 & 2880 & 39.3 & 3492 \\
\hline 4 & Obergurgl & 1883 & 46.8717 & 10.9998 & 73 & 2849 & 28.2 & 3537 \\
\hline 5 & Huben $(1,2,4)$ & 1186 & 47.0508 & 10.9598 & 517 & 2700 & 15.7 & 3768 \\
\hline 6 & St. Leonhard & 1337 & 47.0796 & 10.8312 & 167 & 2613 & 15.5 & 3768 \\
\hline 7 & Hinterbichl & 1321 & 47.0026 & 12.3380 & 107 & 2600 & 14.3 & 3666 \\
\hline 8 & Innergschlöß & 1687 & 47.1099 & 12.4551 & 39 & 2590 & 29.4 & 3666 \\
\hline 9 & Tumpen $(1,2,4,5,18)$ & 924 & 47.1707 & 10.9031 & 786 & 2579 & 11.8 & 3768 \\
\hline 10 & Ritzenried (6) & 1095 & 47.1329 & 10.7711 & 220 & 2544 & 13.2 & 3768 \\
\hline 11 & Neukaser & 1824 & 47.0225 & 11.6877 & 24 & 2499 & 9.6 & 3440 \\
\hline 12 & Tauernhaus (8) & 1504 & 47.1037 & 12.4990 & 60 & 2474 & 19.4 & 3666 \\
\hline 13 & Spöttling & 1486 & 47.0106 & 12.6358 & 47 & 2473 & 10.6 & 3535 \\
\hline 14 & Kühtai & 1902 & 47.2124 & 10.9994 & 9 & 2448 & 0.0 & 3016 \\
\hline 15 & Galtür-Au & 1544 & 46.9988 & 10.1747 & 98 & 2411 & 5.7 & 3332 \\
\hline 16 & Waier (7) & 931 & 46.9798 & 12.5290 & 285 & 2376 & 8.4 & 3666 \\
\hline 17 & Sulzau & 882 & 47.2185 & 12.2508 & 81 & 2354 & 17.2 & 3586 \\
\hline 18 & Fundusalm & 1600 & 47.1492 & 10.8909 & 13 & 2336 & 0.0 & 3097 \\
\hline 19 & See i. P. & 1019 & 47.1051 & 10.4541 & 385 & 2303 & 1.6 & 3397 \\
\hline 20 & Habach & 880 & 47.2322 & 12.3276 & 45 & 2117 & 6.9 & 3211 \\
\hline 21 & Mallnitz & 1174 & 46.9661 & 13.1835 & 85 & 2081 & 0.6 & 3280 \\
\hline 22 & Steeg & 1113 & 47.2643 & 10.2867 & 248 & 1951 & 0.0 & 2808 \\
\hline 23 & Bad Hofgastein & 837 & 47.1456 & 13.1184 & 221 & 1937 & 1.3 & 3188 \\
\hline 24 & Haidbach & 888 & 47.2377 & 12.4921 & 75 & 1915 & 0.0 & 2922 \\
\hline 25 & Rauris & 917 & 47.2233 & 12.9999 & 242 & 1841 & 1.6 & 3220 \\
\hline 26 & Vorderhornbach & 958 & 47.3842 & 10.5389 & 64 & 1726 & 0.0 & 2592 \\
\hline 27 & Hopfreben & 943 & 47.3144 & 10.0416 & 42 & 1701 & 0.0 & 2593 \\
\hline 28 & Wagrain & 849 & 47.3102 & 13.3112 & 91 & 1594 & 0.0 & 2550 \\
\hline 29 & Viehhofen & 861 & 47.3487 & 12.7448 & 151 & 1550 & 0.0 & 2325 \\
\hline 30 & Mellau (27) & 673 & 47.3881 & 9.8790 & 229 & 1494 & 0.0 & 2351 \\
\hline 31 & Laterns & 830 & 47.2956 & 9.7195 & 33 & 1475 & 0.0 & 1963 \\
\hline 32 & Ehrwald & 958 & 47.4150 & 10.9159 & 88 & 1467 & 0.0 & 2874 \\
\hline
\end{tabular}

area together with the meteorological stations used and annual streamflow trends.

\section{Methods}

\subsection{Detection of annual streamflow trends and timing changes}

\subsubsection{Trends of annual streamflow averages}

First, we derived trends of annual streamflow to understand whether the overall yearly water availability changes while there is no information about seasonal changes. For this purpose, annual averages of streamflow were first calculated and later tested on trend significance and magnitude. To compute trend significance, we applied the Mann-Kendall test, considering autocorrelation and cross-correlation. Trend magni- tude was calculated using Sen's slope estimator. The MannKendall test and Sen's slope estimator are standard methods in hydroclimatology. For an in-depth description, see Appendix A.

Afterwards, both significant and insignificant annual trends were plotted on a map of the study area and against the mean watershed altitude. Lastly, general change patterns were identified.

\subsubsection{Minimum detectability}

To cope with the problem that trends may exist but not get detected because of a low signal-to-noise ratio, we calculated minimal detectable trends $\left(\Delta_{\mathrm{MD}}\right)$ as proposed by Morin (2011). To calculate the $\Delta_{\mathrm{MD}}$ of a given time series, we used the relationship that is represented in Fig. 6 of Morin (2011). This is justified, as the minimal detectable 


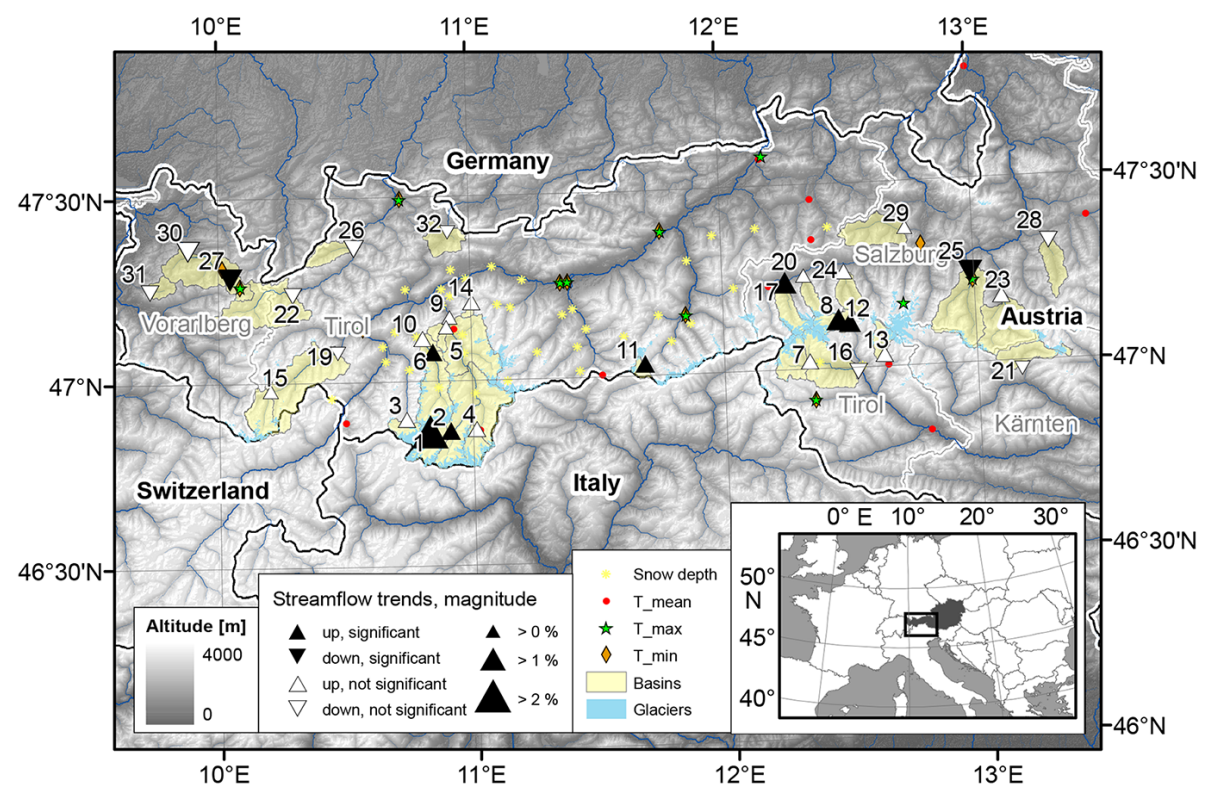

Figure 1. Study area with meteorological stations, watershed boundaries, glaciers and trends of mean annual streamflow in percent change per year (period: 1980-2010; significance level: $\alpha=0.1$ ). Station ID next to the triangles.

trend does not depend on the magnitude of the data. The plot displays the change of the probability of significant trend detection versus signal-to-noise ratio $(S / N)$ and record length $(R)$, averaged over all previously simulated trend values. For a given time series with a given record length it is then necessary to look up the $S / N$ that fits the red contour in the figure, i.e. the $S / N$ at which the probability computed reaches the 0.5 threshold. This $S / N$ is then transferred into $\Delta_{\mathrm{MD}}$ using:

$\Delta_{\mathrm{MD}}=\frac{S / N \cdot \sigma(X)}{R}$,

where $\sigma(X)$ is the standard deviation of the series of averaged observations (e.g. average annual streamflow).

\subsubsection{Streamflow timing changes}

To detect changes of the timing of seasonal streamflow, we used the approach of Renner and Bernhofer (2011). Here, a first order Fourier form model is fitted to runoff data $x$ with $n$ observations per year (Stine et al., 2009; Renner and Bernhofer 2011):

$Y=\frac{2}{n} \sum_{j=1}^{j=n} e^{2 i \pi(j-0.5) / n}\left(x_{j}-\bar{x}\right)$.

From the complex valued $Y$, we estimate the phase $\Phi_{x}=\tan ^{-1}(\mathcal{R}(Y) / \mathcal{I}(Y))$ from the real and imaginary parts of $Y$. The annual phase of a variable describes the timing of its maximum within a given year. The amplitude $A_{x}=|Y|$ describes its range. By applying this harmonic filter to each year of data, we obtained an annual series of phase and amplitude which is further tested for trends.

The approach was considered suitable for our purposes as well, as all of the annual hydrographs in our data set follow a distinct seasonal cycle with strong streamflow maxima in summer and minima in winter. Fourier form models are a more robust measure than other commonly used indicators, such as the centre of volume (Whitfield, 2013; Renner and Bernhofer, 2011). For further reading on this method, see Stine et al. (2009).

\subsection{Trend attribution via subseasonal examinations of streamflow changes}

\subsubsection{Trends and characteristic dates}

To understand the relationship between streamflow trends and the variables that cause these trends, we derived high temporal resolution trends of streamflow on the one hand as the target variable and both (1) the trends and (2) characteristic dates (CDs) of explanatory variables on the other hand. We assume that it is possible to represent certain processes via these trends and the CDs. If streamflow trends and the trends and CDs of temperature and snow depth occur at the same time, we suppose that this might be an indicator for one of the causes of the $Q$ trends.

1. Initially, trends of filtered streamflow data in daily resolution were derived. This approach enables the detection of finer temporal changes compared to the conventional annual or seasonal Mann-Kendall trend test. The 30 -day moving average (30DMA) trends of $Q, T_{\text {mean }}$, 
$T_{\min }, T_{\max }$ and SD were calculated in the following way: at first, the station data set under consideration was filtered using a 30-day moving average. Then a time series of each DOY for the years 1980-2010 is derived which we then test for trends on the basis of the Mann-Kendall trend test and Sen's slope estimator (see Appendix A). This procedure yields a 365 -value data set per station, which provides information on significance and magnitude of the 30DMA trend for every day of the year. These series allowed us to pinpoint the emergence, direction and magnitude of trends within the course of the year. In addition, daily field significances show during which DOYs the trend patterns found were significant overall. The approach of trend detection via moving averages was similarly applied in Western US by Kim and Jain (2010) and Déry et al. (2009), however, they used only 3- and 5-day moving averages and they analysed trends in streamflow. In contrast, the 30-day moving average windows reduce daily fluctuations considerably. With this, the influence of single events on a specific DOY, which might cause erroneous trends, is reduced as well.

2. Next to the trends, characteristic dates of the annual cycle of $Q, T_{\text {mean }}, T_{\min }, T_{\max }$ and SD were derived. To calculate these CDs, all data sets were first smoothed by a 30-day moving average. Through this, comparability to the 30DMA trends is ensured and a more robust estimate of the $\mathrm{CD}$ is obtained because of reduced fluctuations. Then we calculated the mean annual cycles for each variable and each station for the years 1980 to 2010 , in a daily resolution. Afterwards we selected the characteristic dates: for streamflow, the DOY of the overall annual maximum streamflow $\left(\overline{\mathrm{DOY}}{\overline{Q_{\max }}}\right)$ was chosen. With regard to the CDs of $T_{\text {mean }}, T_{\min }$ and $T_{\max }$, we selected the average DOY when temperature passes the freezing point in spring and autumn $\left(T=0{ }^{\circ} \mathrm{C}-\right.$ mean DOY when $T>-0.2$ and $T<+0.2^{\circ} \mathrm{C}$ ), as this point is crucial for multiple hydroclimatological processes in the watershed $\left(\overline{\mathrm{DOY}_{0^{\circ}} T_{\text {mean } / \min / \max }}\right)$. Concerning snow depth, the average DOY of the annual maximum snow depth was chosen to indicate the date of the average start of the snowmelt in the watersheds $\left(\overline{\mathrm{DOY}_{S D_{\max }}}\right)$.

The CDs of $T_{\text {mean }}, T_{\min }, T_{\max }$ and SD had to be fitted to the average altitudes of the watersheds. For this purpose, the average $\mathrm{CD}$ of each station was depicted as a function of station altitude. As all the CDs analysed had an approximate linear relationship with altitude, the DOYs of the trends and thresholds were transferred to the mean altitudes of the watersheds on the basis of a linear regression model.

\subsubsection{Linear model identification}

An empirical statistical model is another tool for analysing which processes cause streamflow trends. Hence, a multiple linear model was fitted to the 30DMA streamflow trends found in the study region. This was restricted to the period between the beginning of March and mid-September (DOY 60 to DOY 250), where $85 \%$ of the total annual streamflow and $84 \%$ of the seasonal streamflow trends (based on absolute trend magnitudes) occur. It is approximately the time between the average annual snow depth maximum (top-of-winter) in spring, before snow and glacier melt starts, and the average start of snow depth increases in autumn.

Based on the previous results of this study, we gathered all possible variables, which then served as predictor variables (independent variables): next to catchment properties such as mean watershed altitude, glacier (forest etc.) percentage or decrease of glaciated area, we used linear regression to transfer long-term average temperatures to the mean watershed altitudes. This means that the assignment of the average temperatures was based on regionally derived temperature lapse rates. We decided not to use snow data, as the assignment of snow depth to certain altitudes is highly uncertain. The $\overline{\Delta T}$ time series were 30DMA temperature trends averaged over all available stations. This was feasible as similar trends concerning timing and magnitude occur at all stations analysed. Similarly to the earlier analyses, all the data sets of hydroclimatological variables were filtered on the basis of 30-day moving averages beforehand.

Different combinations were first tested via a heuristic search based on the $\mathrm{R}$ package glmulti (version: 1.0.7, Calcagno and de Mazancourt, 2010). Later, the model with the best performance in terms of an information criterion was chosen.

\subsubsection{Hourly trends}

To get an impression of the changes on a subdaily scale and support the previous statements based on seasonal trends, we analysed hourly streamflow and temperature data. We selected several gauges that were representative for the area (Gepatschalm, Obergurgl, Tumpen; ID no. 3, 4 and 9; Table 1) with differing glacier percentages (39.3, 28.2 and $11.8 \%$ ). Obergurgl and Tumpen are located in the Ötztal valley; Gepatschalm is located in an adjacent valley. The data were available only in the period 1985 to 2010 (compared to 1980 to 2010 for the earlier analyses). The applied methods are analogous to the previous analyses: for each station, DOY and hour, 30DMA trends were calculated and depicted in a similar way to the seasonal 30DMA trends. However, compared to the earlier plots, the ordinate is now changed from rank of station altitude to hour of day. Accordingly, the averages of 1 day's trend magnitudes (the entire $y$ axis) are 
a) $\Delta Q_{\overline{y e a r}}$ in percent

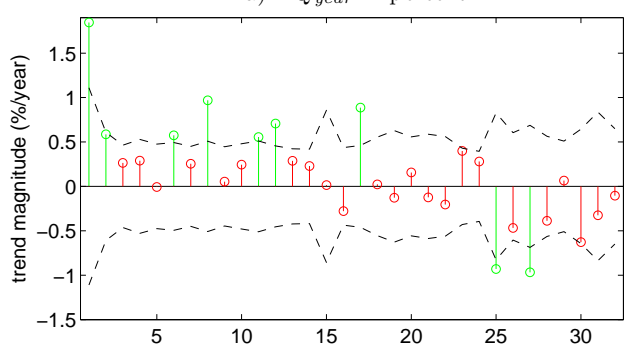

c) $\Delta Q_{\text {phase }}$

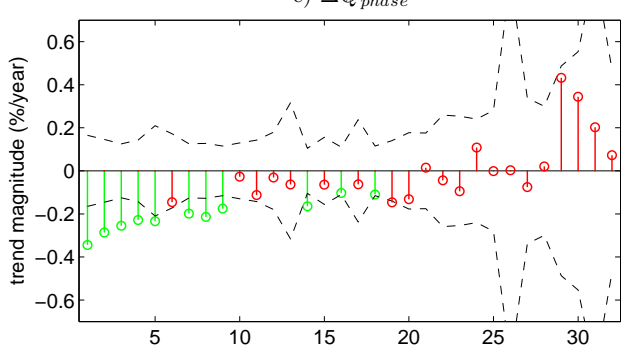

b) absolute $\Delta Q_{\overline{y e a r}}$

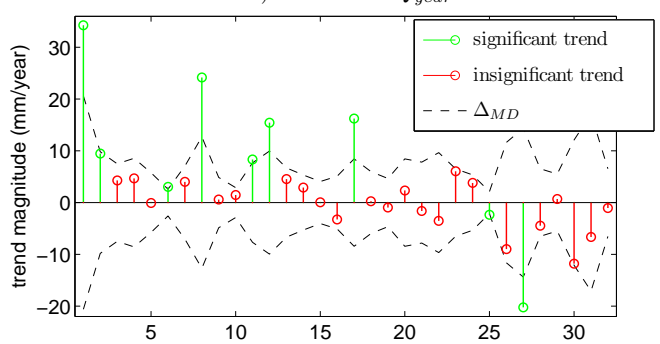

d) $\Delta Q_{\text {amplitude }}$

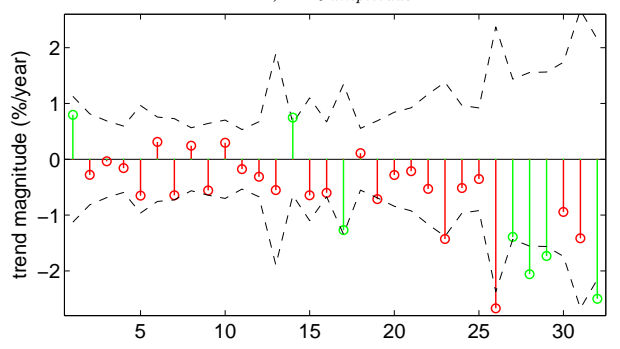

Figure 2. Trend magnitude (percent and absolute values) versus station ID (sorted by rank of mean watershed altitude $-1=$ highest).

the same values as the trend magnitudes of one station in the earlier plot.

\section{Results}

The results and discussion sections are structured according to the analyses that were conducted (for a schematic illustration, see Fig. A1).

In the first part, we analysed trends of annually averaged streamflow and trends of the results of the Fourier form models. For this purpose, three different approaches were used: (1) mapping of annual trends in the study area, (2) analyses of a potential altitude dependency of the annual trends and (3) analyses of trends of the phase and the amplitude of the annual streamflow cycle. Based on the outcomes of these analyses, we defined research hypotheses (see Sect. 1).

In the second part, we derived trends of filtered daily streamflow, temperature (mean, maximum and minimum) and snow depth, to support our hypotheses. These seasonal trends were then further applied in the attribution approaches: (1) a combination of characteristic dates and trends, (2) a multiple regression model for streamflow trends and (3) hourly trends.

\subsection{Detection of trends based on annual averages, phases and amplitudes}

Figure 1 displays the annual streamflow trends $\left(\Delta Q_{\overline{\text { year }}}\right)$, which were calculated from the change per year divided by mean annual streamflow, on a map of the study area. Roughly two-thirds of $\Delta Q_{\overline{\text { year }}}$ in the study region are not significant at a significance level of $\alpha=0.1$, and no field signifi- cance was detected. The mapped trends neither depict any clear spatial trend pattern nor show strong overall changes in alpine hydrology. However, when presenting all annual streamflow trends, significant and insignificant, versus station ID as a rank of mean watershed altitude, another impression stands out (Fig. 2): it seems that higher-altitude watersheds depict mostly positive trends, whereas lower-altitude watersheds show negative trends. The watersheds at midaltitudes show both positive and negative trends. Only nine out of 32 trends, where the change signal is high enough compared to the noise, are significant. The other ones are below the corresponding $\Delta_{\mathrm{MD}} \mathrm{s}$. This applies both for trends calculated from the change per year divided by mean annual streamflow (Fig. 2a) and for trends derived from absolute values (Fig. 2b). Concerning the phase of streamflow, there is a clear signal of decreasing trends at higher stations (Fig. 2c), representing an earlier onset of spring freshet. At lower stations, phase trends are insignificant, mostly due to higher signal-to-noise ratios, which increase the minimal detectable trend (dashed lines). The trends of the streamflow amplitudes show a similar behaviour to the trends of annual $Q$ averages, but shifted to mostly negative trends (Fig. 2d): in general, amplitudes are decreasing, but less so at higher stations and more so at lower stations.

All the trends mentioned above show an explicit correlation with the mean watershed altitude, which does not depend on trend significance (Table 2). Note that the Pearson's correlation coefficients of significant trends are based on fewer values, so in this case higher correlation coefficients are easier to obtain. All of the correlations tested significant at the $\alpha=0.1$ level. 


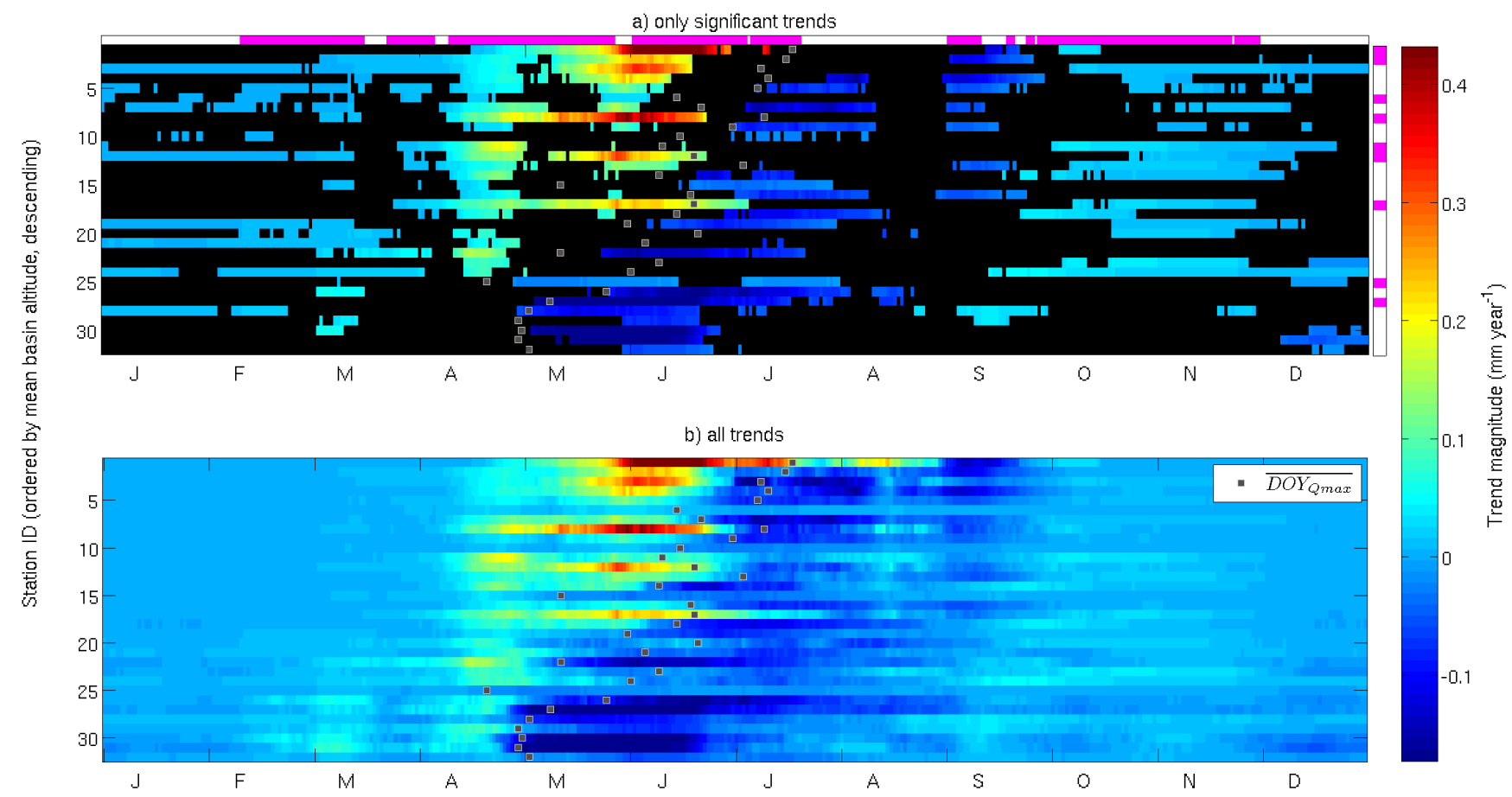

Figure 3. Seasonal distribution of daily streamflow trends (period: 1980-2010; significance level: $\alpha=0.1$ ); (a) 30DMA trend magnitude, only where significant trends are detected (dark blue if not significant); (b) significant and insignificant 30 DMA trend magnitudes; bar above upper diagram: pink if the 30DMA trends are field-significant; bar on the right of upper diagram: pink if the annual streamflow trend of the corresponding station is significant.

Table 2. Pearson's $r$ between annual streamflow trends and mean watershed altitude.

\begin{tabular}{lccc}
\hline & $\begin{array}{c}\text { Significant } \\
\text { trends only }\end{array}$ & $\begin{array}{c}\text { Insignificant } \\
\text { trends only }\end{array}$ & Both \\
\hline$\Delta Q_{\overline{\text { year }}}$, percent & 0.84 & 0.54 & 0.68 \\
$\Delta Q_{\overline{\text { year }}}$, absolute & 0.81 & 0.65 & 0.62 \\
$\Delta Q_{\text {phase }}$ & 0.86 & 0.68 & 0.83 \\
$\Delta Q_{\text {amplitude }}$ & 0.87 & 0.74 & 0.76 \\
\hline
\end{tabular}

\subsection{Trend attribution via subseasonal trends}

\subsubsection{Trends and characteristic dates of streamflow}

As already found in Kormann et al. (2014), coherent 30DMA streamflow trend patterns appear when plotted against the time of year and altitude (Fig. 3a). We refer to the groups discernible in these plots as "trend patterns". Streamflow clearly rises in spring, followed by decreases in summer; both trend patterns depend on watershed altitude. Another obvious pattern is the positive one in autumn, roughly from October to December; this one was not found to be altitudedependent. Over most of the time, the 30DMA trends are field-significant (Fig. 3a, bar above diagram), meaning the trend patterns as a whole are statistically more frequent than expected by random chance.

At higher-altitude basins, significant $Q$ trends in annual averages $\left(\Delta Q_{\overline{\text { year }}}\right)$ were found especially where $\Delta Q_{30 \mathrm{DMA}}$ in spring have high values (Fig. 3a, bar on the right). At lower stations, only two significant $\Delta Q_{\overline{\text { year }}}$ were detected, both at watersheds where hardly any positive $\Delta Q_{30 \mathrm{DMA}}$ were detected.

When analysing all 30DMA streamflow trends (Fig. 3b), not only the significant ones, the designated trend patterns are even more obvious. An additional positive trend pattern occurs in mid-August at higher stations, though this one is less evident than the others.

The CD that indicates the DOY when the long-term annual streamflow peak occurs $\left(\overline{\mathrm{DOY}_{Q_{\max }}}\right)$ is often found after the increasing trends in spring and before the decreasing trends in summer (Fig. 3b), which is especially true for lower stations. This means that increasing $Q$ trends mostly occur during the rising limb and decreasing ones during the falling limb of the seasonal hydrograph. These patterns correspond to a shift in the hydrograph and thus a decreasing trend in the phase of streamflow timing. 
a) $\overline{D O Y_{0}{ }^{\circ} \text { TmeanSpring }}$

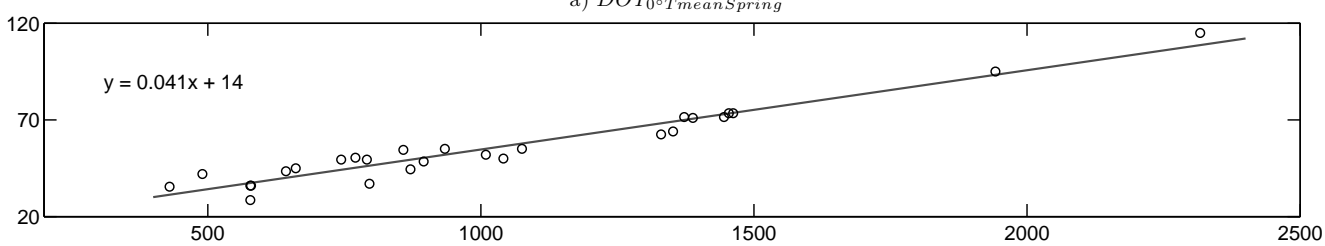

b) $\overline{D O Y_{0}^{\circ} \text { TmeanAutumn }}$

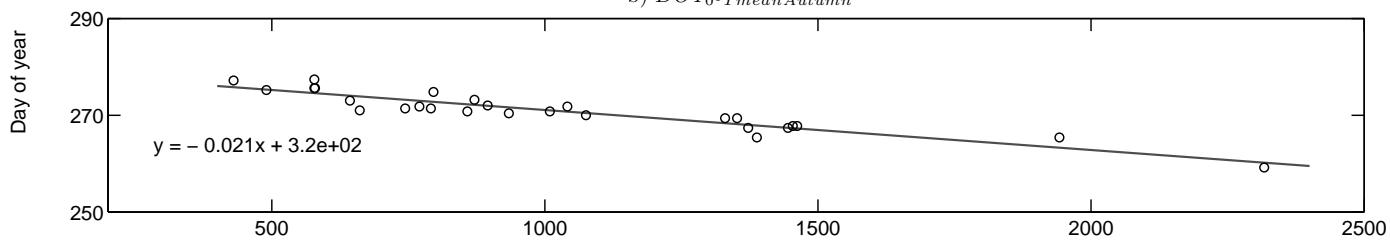

c) $\overline{D O Y_{S D \max }}$

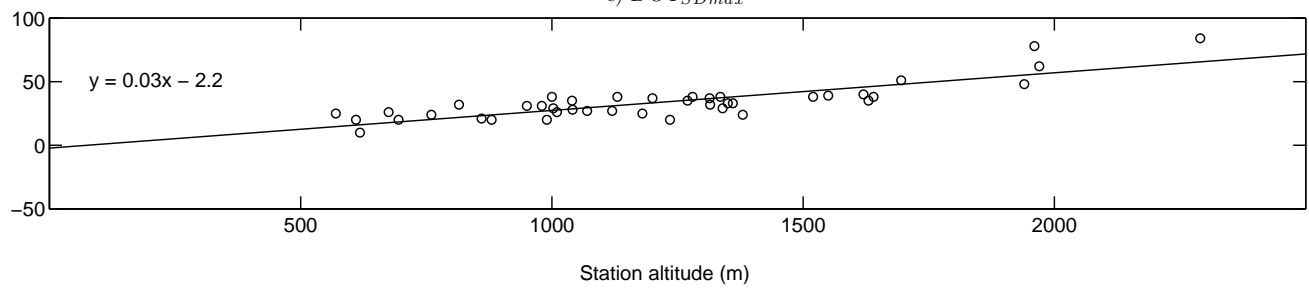

Figure 4. (a) Station altitude vs. $\overline{\mathrm{DOY}}$ of daily $T_{\text {mean }}$ passing the freezing point in spring; (b) same as (a), but for autumn; (c) station altitude vs. $\overline{\mathrm{DOY}}$ of annual SD maximum; all graphs with the line of best fit and corresponding equation. DOYs are calculated as averages of the period 1980-2010.

\subsubsection{Characteristic dates and trends of temperature and snow depth}

The analysis on elevation dependence of the CDs of $T$ and SD derived from climate stations is presented in Fig. 4. The average DOYs of daily $T_{\text {mean }}, T_{\min }$ and $T_{\max }$ surpassing the freezing point $\left(\overline{\mathrm{DOY}_{0}{ }^{\circ} T_{\text {mean } / \min / \max }}\right)$ all depend on altitude, in spring as well as in autumn (Fig. 4a and b). The same applies for the average DOY of the annual snow depth maximum $\left(\overline{\mathrm{DOY}_{\mathrm{SD}_{\max }}}\right.$, Fig. $\left.4 \mathrm{c}\right)$. Almost all the characteristic dates show a linear relationship with station altitude. Thus this linear relation is being used to establish a representative, long-term $\mathrm{CD}$ for each watershed using the mean catchment altitude.

Regarding trends, there are differences between the $T_{\min }$, $T_{\max }$ and $T_{\text {mean }}$ trends, but these mostly concern the trend magnitude, not its direction or timing (Fig. 5a-c). Comparing single stations with each other, it is obvious that the $T$ trends appear in temporal clusters that start and end during similar DOYs. Four main patterns of field-significant positive $T$ trends are evident: (1) mid-March until the beginning of May, (2) mid-May until the end of June, (3) the beginning of July until mid-August and (4) the beginning of October until mid-November. The $T_{\max }$ trends are roughly twice as intense as the ones for $T_{\min }$ and $T_{\text {mean }}$, but field significance was detected only in two of the four highlighted segments (upper bar in Fig. 5). For most of the stations, the magnitude and days of occurrence are similar, meaning there is no altitude dependence of the $T$ trend signal.
Figure 5d shows the analogous trend results for the explanatory variable snow depth (SD). Strong negative SD trends dominate the results; however, some positive trends occur at two upper stations and around November at many of the stations. One main cluster of field-significant trends in spring can be distinguished, which also indicates that local significant trends were found only in spring.

\subsubsection{Comparison of the timing of trends and characteristic dates of streamflow with those of temperature and snow depth}

Spring $\left(\overline{\mathrm{DOY}_{0^{\circ} T_{\max } \text { Spring }}}\right.$ to $\overline{\left.\mathrm{DOY}_{0^{\circ} T_{\text {min Spring }}}\right)}$ : $\overline{\mathrm{DOY}_{0} T_{\text {max Spring }}}$ and $\overline{\mathrm{DOY}_{S D_{\max }}}$ appear during similar days as the first $Q$ trends (Fig. 5e). Between $\overline{\mathrm{DOY}_{0}{ }^{\circ} T_{\max } \text { Spring }}$ and $\overline{\mathrm{DOY}_{0} T_{\text {mean Spring }}}$, the $Q$ trend magnitudes further increase, most of them in shifts, i.e. first the lower basins around early March and the later ones in April. In April, there is a general major peak in the observed streamflow trends at basically all of the watersheds. This is also the time when field-significant SD trends turn up at the majority of stations (Fig. 5d). During this period, it seems that there is an elevation-dependent trend pattern between $\overline{\mathrm{DOY}^{\circ} T_{\max \text { Spring }}}$ and $\overline{\mathrm{DOY}_{0^{\circ}} T_{\text {min Spring }}}$, superposed by an elevation-independent one.

The overall strongest $Q$ trends occur at high-lying watersheds after the average daily $T_{\text {mean }}$ is positive and when $T_{\min }$ is still negative. $T$ trends are also at their highest levels at 


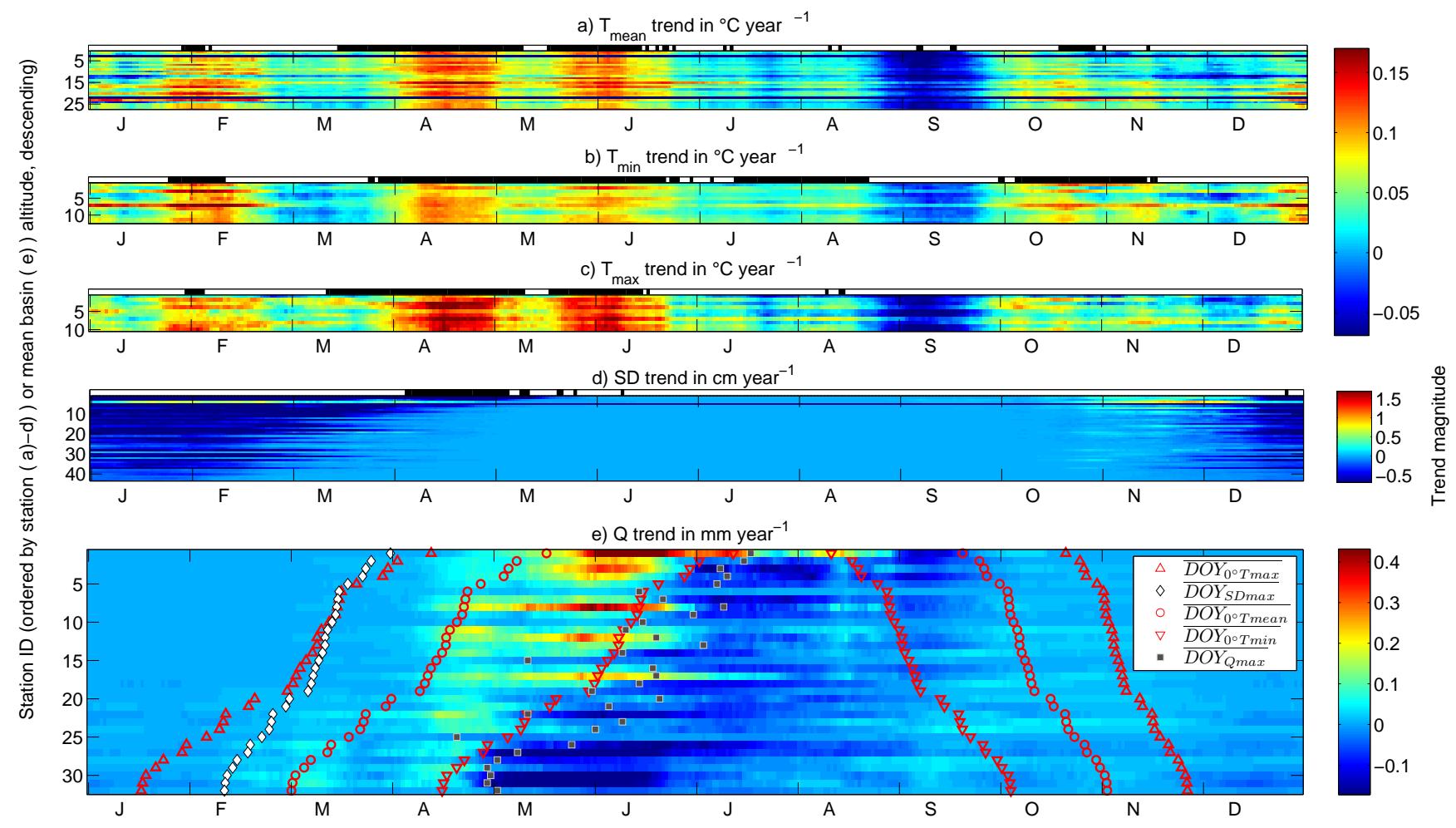

Figure 5. (a)-(d) Seasonal distribution of daily mean (a), minimum (b) and maximum (c) temperature, (d) snow depth trend magnitudes and (e) streamflow trends (with characteristic dates) (1980-2010); bar above diagram: black if field-significant.

this time of year, and the dynamics of the $T$ trends resemble the ones in the $Q$ trends with overall maxima between end of May and beginning of June. Pearson's $r$ between all single

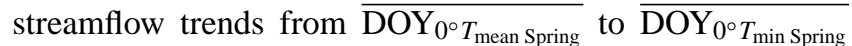
and the corresponding glacier percentage in the watershed was calculated at 0.74 , which means the strongest $Q$ trends turn up mostly at watersheds that are highly glaciated.

Some trends at mid-altitude watersheds stand out with high magnitudes and long persistence (at gauges No. 8, 12, 17). All these rivers are fed by glaciers that originate from the Hohe Tauern region (eastern side of the study region, cf. Fig. 1).

Summer $\left(\overline{\mathrm{DOY}_{0}{ }^{\circ} T_{\min S p r i n g}}\right.$ to $\left.\overline{\mathrm{DOY}_{0^{\circ} T_{\min \text { Autumn }}}}\right)$ : during summer, many of the $Q$ trends observed are negative, with the strongest ones at lower basins after $T_{\min }$ has crossed the freezing point in spring. At higher, glaciated watersheds, negative $Q$ trends occur only after positive $Q$ trends have diminished. Field-significant $T$ trends go along with these $Q$ trends; both of them are especially strong from mid-May until mid-June.

Autumn ( $\overline{\mathrm{DOY}_{0}{ }^{\circ} T_{\min \text { Autumn }}}$ to $\left.\overline{\mathrm{DOY}_{0^{\circ} T_{\max \text { Autumn }}}}\right)$ : in autumn there are two main patterns with opposing signs: negative $Q$ trends at higher-altitude watersheds in September and slightly positive $Q$ trends at all watersheds around October. In September, the negative $Q$ trends coincide with negative $T$ trends. In October, positive field-significant trends in $T_{\text {mean }}$ and $T_{\min }$ were detected. $\mathrm{DOY}_{0^{\circ}} T_{\max \text { Autumn }}$ and $\mathrm{DOY}_{0^{\circ}} T_{\text {min_Autumn }}$ do not border the $Q$ trends as clearly as in spring.

Winter $\left(\overline{\mathrm{DOY}_{0^{\circ} T_{\max } \text { Autumn }}}\right.$ to $\left.\overline{\mathrm{DOY}_{0^{\circ} T_{\max } \text { Spring }}}\right)$ : all throughout winter, there is hardly any streamflow persisting in the highest watersheds. This is also reflected in the fact that there are only few trends at the upper 20 watersheds. In contrast, minor streamflow trends exist at lower watersheds; however, there is no clear positive or negative pattern and trend magnitudes are small.

\subsubsection{Empirical statistical model for streamflow trends}

The heuristic model selection based on the information criteria identified the most relevant explanatory variables. The best performance (the adjusted $R^{2}$ was calculated as 0.70 ) was achieved with the model in Eq. (3). Note that we normalized the trend of streamflow at a specific DOY $\left(\Delta Q_{30 \mathrm{DMA}}\right)$, as well as the first derivative of the seasonal 30DMA $Q$ average $\left(\overline{Q_{30 \mathrm{DMA}}}\right)$ by the long-term average streamflow at a specific DOY $\left(\overline{Q_{30 \mathrm{DMA}}}\right)$. 


$$
\begin{aligned}
\frac{\Delta Q_{30 \mathrm{DMA}}}{\overline{Q_{30 \mathrm{DMA}}}} & =0.0017-0.096 \overline{\Delta T_{\min }}+0.0036 \frac{\overline{Q_{30 \mathrm{DMA}}}}{\overline{Q_{30 \mathrm{DMA}}}} \\
& +0.59 \frac{A_{\text {ice }}}{A_{\mathrm{tot}}} \overline{\Delta T_{\min }}
\end{aligned}
$$

From the a priori selected explanatory variables, we found that only three variables are required to predict the streamflow trend at a specific day of the year: minimum temperature, the first derivative of streamflow indicating rising or falling streamflow conditions as well as the percentage of glaciated area in a watershed $\left(A_{\text {ice }} / A_{\text {tot }}\right)$ multiplied by the 30DMA $T_{\min }$ trend in ${ }^{\circ} \mathrm{C}$ per year for the corresponding DOY.

The prerequisites of a linear model (homoscedasticity, normally distributed residuals) were checked via standard diagnostic plots. The large majority of the predicted trend values were in accordance with the observed ones (Fig. 6); only several very high values $(>4 \%)$ could not be simulated well. All of these values were found at the gauge with the highest percentage of glaciated area in the watershed (ID 1, Vernagt). Also at this gauge, there are several occasions when observed trends are zero although the model predicts that there will be a trend. This happens during earlier DOYs, when there is no discharge as all water in the basin is still frozen.

\subsubsection{Analysis of hourly streamflow trends}

The overall results of the hourly $T$ and $Q$ trend analysis show similar structures to the seasonal one (Fig. 7). Concerning $Q$, there are certain periods when subdaily dynamics in $Q$ trends are obvious, like the period from mid-May until mid-June. During other periods, there is hardly any difference between the trends at different times of day.

More specifically, from mid-March to early May, there is merely a diurnal dynamic in the $Q$ trends. Positive $T$ trends without any explicit diurnal dynamic occur at the same time. In contrast, from mid-May until mid-June there is a clear dependency between the positive trends in the afternoon, the time of day and the watershed analysed: the lower the watershed and the smaller the glacier percentage, the later the $Q$ trends occur and the lower are their magnitudes.

\section{Discussion}

\subsection{Detection of trends based on annual averages, phases and amplitudes}

The positive (and often significant) annual streamflow trends at higher-altitude glaciated watersheds might be a sign that glaciers in Western Austria are still in the phase, where overall streamflow still rises due to increasing glacial melt. This corresponds well with other studies in the European Alps (Pellicciotti et al., 2010; Bard et al., 2011; Braun and EscherVetter, 1996).

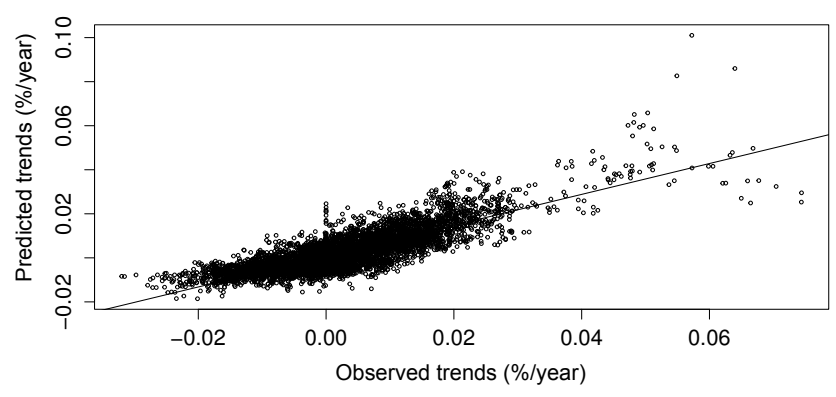

Figure 6. Scatterplot of predicted vs. observed streamflow trends in percent per year on the day considered.

Contrary to that, the annual $Q$ trends at lower-altitude basins are often insignificant and negative. Rising temperatures change hydroclimatic conditions in the basins, resulting in e.g. shorter winters, higher ET, higher infiltration and alternating storage capacities (Berghuijs et al., 2014). Hence, less water contributes directly to runoff, which might be a potential cause for the negative annual trends observed in lower-altitude basins.

The ambiguous change signals of annual $Q$ trends at midaltitude watersheds with little or no glacier cover might be a result of a balancing effect of increased glacial melt and rising ET. Hence, trends are mostly lower than the corresponding minimal detectable trends, so in many cases, no significance is detected. This agrees with Birsan et al. (2005), who found no increasing annual $Q$ trends in basins with a glacier cover of less than $10 \%$.

The present analysis of annual streamflow trends shows once more that it is important to include insignificant trends in the interpretation of the results. It might not have been possible to find the overall altitude-dependent patterns when only looking at significant results. However, it is crucial to interpret the insignificant trend results more carefully.

The analyses of $Q$ phase and $Q$ amplitude highlight the different behaviour of higher- and lower-altitude watersheds under climate change. We observe significant shifts towards earlier streamflow timing in the upper catchments, whereas the amplitudes decrease in the lower catchments. However, the Fourier form models are increasingly uncertain in lower catchments where the annual hydrograph deviates from a harmonic function. Therefore, a seasonal trend analysis is required to detect potential regime changes.

\subsection{Trend attribution via subseasonal trends}

\subsubsection{Comparison of the timing of trends and characteristic dates of streamflow with those of temperature and snow depth}

Spring: the ambiguous structure of the mid-January to April streamflow increases (altitude-dependent vs. altitude- 
a) T trend at Vernagt in ${ }^{\circ} \mathrm{C}$ year ${ }^{-1}$

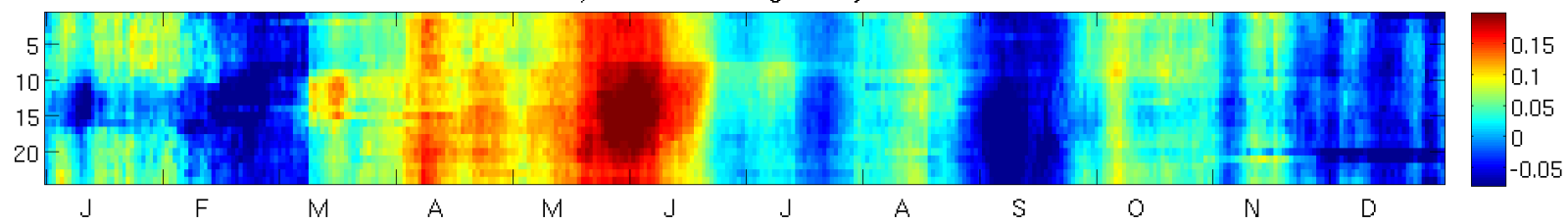

b) $Q$ trend at Gepatschalm in mm year ${ }^{-1}$

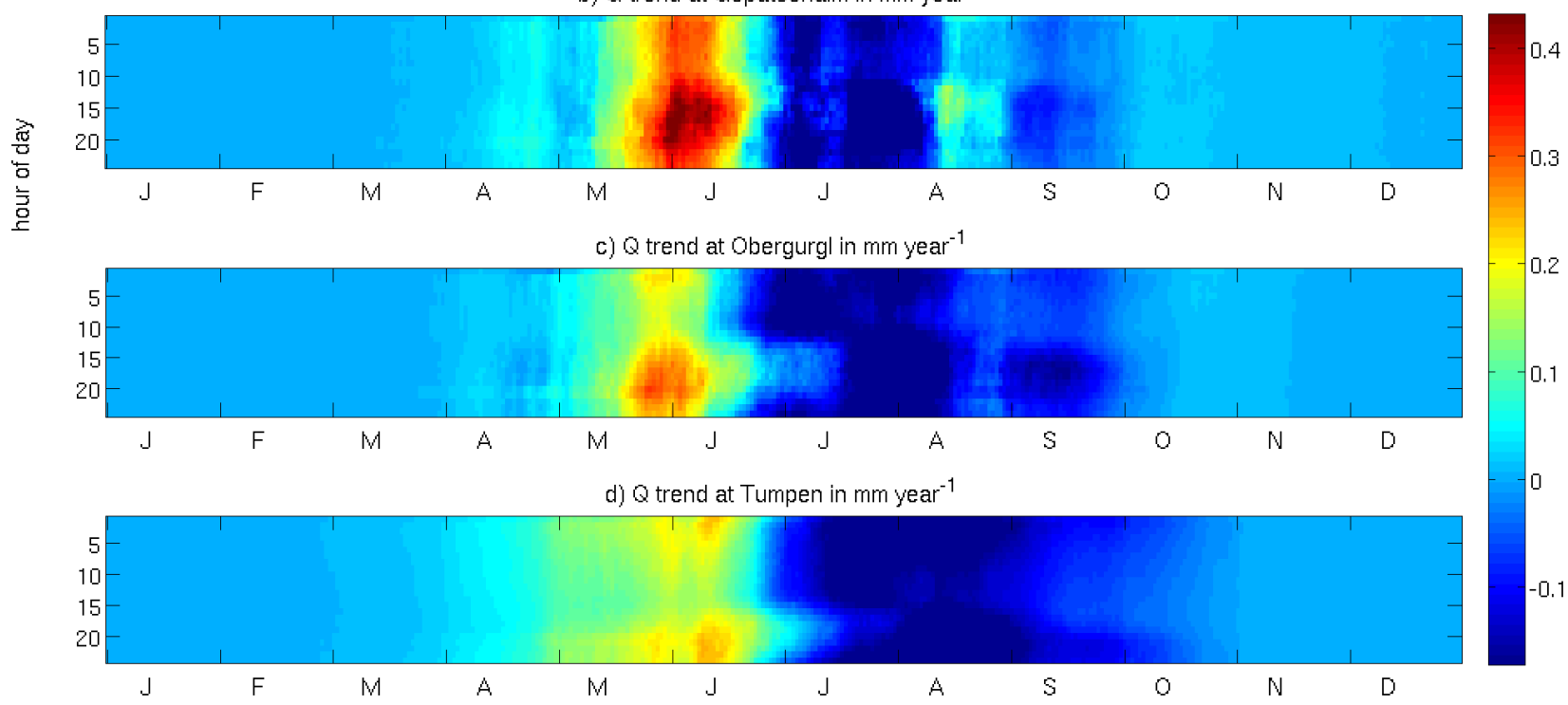

Figure 7. Seasonal distribution of hourly trend magnitudes (1985-2010): (a) $T$ at Vernagt; (b) $Q$ at Gepatschalm; (c) $Q$ at Obergurgl; (d) $Q$ at Tumpen.

independent trends) is possibly caused by the following two mechanisms.

On the one hand; temperatures need to rise above freezing level to allow for snowmelt initiation. This DOY depends on the altitude of the snowpack (e.g. Reece and Aguado (1992) found an altitudinal melt onset gradient of 4 days per $100 \mathrm{~m}$ in the Sierra Nevada). With $T$ trends occurring during the whole spring, snowmelt initiation shifted to earlier DOYs, which probably caused the elevation-dependent trend pattern.

On the other hand, the average spring rise of streamflow occurs at most of the watersheds in the study region during similar days of the year (see Kormann et al., 2014), which implies that snowmelt starts simultaneously at different altitudes. Hence, it seems that snowmelt in our study region is highly driven via weather patterns and their hydrological effects such as rain-on-snow events that influence e.g. whole valleys and not just single altitude bands. Garvelmann et al. (2015) showed that snowmelt is strongly driven via rain-on-snow events and highly depends on the previous moisture of the snow pack. Lundquist et al. (2004) observed altitude-independent snowmelt in single years. With increasing $T$, rain-on-snow events might have turned up earlier in the season, thus causing the elevation-independent trend pattern during spring.
It is possible that in some years the first mechanism is stronger and in other years the second, with both of them moving to earlier DOYs.

The May to June streamflow increases at upper watersheds are the strongest $Q$ trends that were found. The similar dynamics of $T$ and positive $Q$ trends during this period suggest a strongly temperature-driven trend cause. Furthermore, not only the high correlation of the $Q$ trend magnitude with watershed glacier percentage but also the fact that many trends in glaciated basins persist when average $T_{\min }$ has already been above $0^{\circ} \mathrm{C}$ for many days (see next section) indicates that these patterns might be caused by increasing glacial melt. The strong $Q$ trends of watersheds in the Hohe Tauern region suggest a particularly high glacial meltdown in this area.

All these evidences suggest that the first spring trend pattern is caused by both earlier snowmelt and less snowfall (Kormann et al., 2014) and the second one is a result of shrinking glaciers due to rising temperatures. Anyway, one has to keep in mind that it is practically impossible to explicitly separate trends caused by snowmelt and the ones caused by glacier melt, as melt at lower glacier parts starts while the upper parts are still covered with snow.

At first glance, glacier melt in May might appear very early in the year when looking at seasonal streamflow com- 
position. However, one has to note that the trends in glacier melt should not be confused with the actual amount of glacier melt: the main ice melt is happening later in the year, but the strongest trends turn up earlier. These $Q$ trends are highly connected to temperature trends, which are also strongest during this time of year (cf. Fig. 5). The results of modelling approaches (e.g. Alaoui et al., 2014) confirm our interpretations and suggest that glacier melt starts even earlier in the year.

Summer: in summer, the snow reservoir has already emptied out in most of the watersheds. The negative $Q$ trends during this time of year are possibly part of the effects of earlier snowmelt timing on streamflow. This shift causes first rising and directly afterwards dropping streamflow trends in spring and summer, which were similarly found for watersheds in western North America by other daily resolved trend analyses (Kim and Jain, 2010; Déry et al., 2009). However, to fully attribute summertime $Q$ decreases, it would be necessary to separate the effects of shifts in snowmelt timing from the effects of lower snow accumulation (and with this, lower snowmelt volumes). This task had been addressed in Déry et al. (2009) by a simple model approach. However, a separation of these effects based on analyses of other observed variables is difficult, as negative $Q$ trends in summer might also have other causes such as higher infiltration, rising ET and changing storage conditions (Berghuijs et al., 2014).

At higher-altitude basins, the negative summertime $Q$ trends are balanced to a certain degree by positive trends due to excess water from glacial melt, which is evident via trends that persist far longer than the $\overline{\mathrm{DOY}_{0}{ }^{\circ} T_{\text {min Spring }}}$. This superimposition might also cause positive $Q$ trends in mid-August at upper stations, maybe because the negative summertime trends have already weakened then. According to Stahl and Moore (2006), the biggest difference in streamflow trends of glaciated and unglaciated basins is found during the month of August. However, in contrast to their study in Canada, we found mainly increasing August $Q$ trends at glaciated watersheds and slightly decreasing ones at unglaciated watersheds.

The altitude dependency of the timing of $\overline{\mathrm{DOY}_{Q_{\max }}}$ highlights the need for highly resolved, subseasonal trend analyses: as upward trends generally occur before and downward trends occur after $\overline{\mathrm{DOY}_{Q_{\max }}}$, a separation of trend statistics in 3 -month periods (spring, summer, autumn, winter), as is usually done in trend studies, might produce ambiguous trend results, especially in summertime.

Autumn: Cahynová and Huth (2009) showed that significant increases in cyclonic circulation types are the major cause for autumn temperature decreases. These negative $T$ trends in turn might have caused the $Q$ decreases at higheraltitude basins in September, as during this time of year the glacier is exceptionally not melting but accumulating. These effects are possibly increased by the negative summertime $Q$ trends due to snow decreases in the previous winter and earlier melt. In contrast, during October, rising $T_{\text {mean }}$ and $T_{\min }$ might cause less snowfall and less snow to be accumulated and hence generate more rainfall-driven runoff during this time of year. This generally agrees with the interpretations in earlier literature (e.g. Déry et al., 2005).

Winter: during winter, $T_{\max }$ is far below zero, so on average no melt processes are possible. However, temperatures might reach above zero in the lower catchment areas of certain watersheds, so positive $Q$ trends could be caused through lower snow accumulation in these watersheds. The negative trends in absolute snow depth might have been caused at the beginning of the winter, so it is plausible that these have no effect on streamflow during mid-winter. These interpretations generally agree with e.g. Scherrer et al. (2004), who attributed SD decreases at lower-altitude stations to $T$ increases rather than changes in precipitation patterns.

\subsubsection{Empirical statistical model for the identification of streamflow trends}

The multiple linear model is able to simulate daily streamflow trends sufficiently well. The predictor $\overline{Q_{30 \mathrm{DMA}}}$ accounts for both positive $Q$ trends in the rising limb of the annual $Q$ cycle (before the annual maximum) and negative trends that turn up in the falling limb (cf. Fig. 3). Reinterpreted as a trend, the term $\overline{Q_{30 \mathrm{DMA}}}$ corresponds to a shift in earlier streamflow timing of 1 day per year. The coefficient $(0.36)$ in our model adjusts this term to the shift found in our data. For the 30-year study period, this counts up to a shift of 10.8 days of earlier streamflow timing, which is similar to shifts reported in the literature. For example, Renner and Bernhofer (2011) report a shift of 10 to 22 days' earlier timing (comparing 1950-1988 and 1989-2009) in the runoff ratio for catchments in the low mountain ranges of Saxony, Germany. Déry et al. (2005) found that annual peak snowmelt discharge appears roughly 8 days earlier (study period 1964-2000); Stewart et al. (2005) detected a shift of 6-19 days (1948-2003), both in North America and based on timing measures such as "centre of volume". However, depending on factors such as the study period, region and methods used, results in previous literature differ strongly.

The predictor " $A_{\text {ice }} / A_{\text {tot }}$ " considers the increased excess water from glacial melt in the model. The selection of this term and not e.g. "decrease of glaciated area" (which has been tested as well) supports the findings of Weber et al. (2009): as glacial melt mostly occurs at the surface, the quantity of melt water generally behaves proportionately to the extent of glaciated area in the watershed, independent of the underlying glacier thickness.

The glacial melt is driven via temperature increases, hence the glacier term includes the 30DMA temperature trends. As the " $A_{\text {ice }} / A_{\text {tot }} \overline{\Delta T_{\min }}$ " term enters the model with a positive coefficient, one can assume that the majority of the glaciers have not yet reached the point when overall streamflow decreases due to diminishing glacier mass. 
The additional single term " $\overline{\Delta T_{\min }}$ " has a negative coefficient, and hence might account for the negative trends in summertime caused by increased ET, higher infiltration and decreased snow cover accumulation. The selection of $\overline{\Delta T_{\min }}$ instead of $\overline{\Delta T_{\max }}$ is somewhat surprising, as one might expect many of the streamflow trends to be strongest during daytime, when temperatures are at their highest. Indeed, the selection makes sense: the ground is potentially frozen once $T_{\min }$ falls below zero. If this is the case, additional energy is necessary for melting during daytime. With a rise in $T_{\min }$, energy that is not needed any more for melting is now available for atmospheric warming in addition to $\overline{\Delta T_{\min }}$ alone.

The advantage that few input data are necessary has also some drawbacks: as the model is very slim, it only captures the main factors that could cause streamflow trends in highly alpine catchments. Contributors such as changes in groundwater or precipitation are not accounted for explicitly, only via their response to the other predictors. In autumn, the model is not able to simulate the actual trends adequately either. However, these trends are small in magnitude and do not influence the overall statements too much.

Furthermore, we found significant autocorrelation in the residuals, as the Durbin-Watson statistic indeed indicated. This is violating the assumptions of independence of linear regression, which often happens when fitting models to time series with a seasonal cycle. The autocorrelation in the residuals precludes statements on confidence bands and significance tests: the standard errors of the regression coefficients are potentially too small, which prevents higher model precision. However, our model stands as an approximation only. We are aware that the model is not perfect, as it is impossible to find all specific causes that explain the streamflow trends in our study region. The model is able to simulate streamflow trends sufficiently well, providing further hints on the causes of $Q$ trends.

\subsubsection{Analysis of subdaily streamflow trends}

The hourly $Q$ trend analysis supports the findings of the earlier analyses. To give more detail, the patterns found might occur for the following reasons: due to the relatively low albedo of glacial ice $(\sim 0.3$ to 0.5$)$ compared to snow $(\sim 0.7$ to 0.9 , Paterson, 1994), glacial melt depends more strongly on incoming radiation than snowmelt. Climate change results in earlier snow-free conditions on glaciers, which in turn cause earlier glacial melt during noontime. The resulting $Q$ trends are temporally delayed with increasing distance from the glacier and their magnitudes decrease with decreasing watershed altitude. This might be due to a generally lower percentage of glaciated area in the lower-altitude basins and a balancing effect of the negative $Q$ trends which is caused by earlier snowmelt, lower snow accumulation and rising ET.

In this context, it is noteworthy that there is no clear subdaily dynamic in the negative trends during DOYs with $T$ increases: with rising ET, one would expect stronger negative
$Q$ reductions at noon due to the maximum necessary radiation input. Either this is balanced via glacial melt or the magnitude of the changes is too small compared to the reductions due to the shift of snowmelt to earlier DOYs.

\subsubsection{Synthesis of the streamflow trend attribution approach}

In the following we synthesize the streamflow trends and potential causes. The overall findings are illustrated with three representative catchments. Figure 8a represents a typical higher-altitude watershed (Gepatschalm, $2880 \mathrm{~m}, 39.3 \%$ glaciated), a mid-altitude, little glaciated watershed (See i. P., $2303 \mathrm{~m}, 1.6 \%$ glaciated.) (Fig. 8b) and a lower-altitude, unglaciated watershed (Ehrwald, $1467 \mathrm{~m}$ ) (Fig. 8c), which are depicted along with the detected trends and their probable main drivers. Our seasonal analyses support the hypotheses that we proposed in the introduction: the subseasonal structure of streamflow trends in higher-altitude, glaciated watersheds corresponds well with the one that might stem from glacier wastage. The overall annual 30DMA trend integral over time (and thus the annual trend) is positive, as additional water in spring enters the basin (Fig. 8a). In loweraltitude watersheds, especially summertime decreases lead to an overall negative annual trend integral (Fig. 8c). In the case where the annual 30DMA trend integral over time is close to zero, the trends are caused by shifts rather than by changes of the overall streamflow amount (Déry et al., 2009). This might be the case in mid-altitude, little glaciated watersheds, where only small changes affect the annual hydrograph (Fig. 8b).

In summary, the two main influences on alpine streamflow are the increased glacial melt and the shift to earlier snowmelt, both driven via temperature increases. This is supported by many studies in alpine regions, where drivers of streamflow changes were identified via modelling approaches (e.g. Barnett et al., 2005). Anyway, we want to emphasize that our analysis is based on observed station data only. For this reason, we consider our statements concerning both the detection and the attribution of the changes to be more robust than results obtained by stand-alone model approaches. However, a few patterns still exist, where streamflow trend attribution via temperature, glacier and snow depth changes is not sufficient and thus the need for further research remains: for example, we could not explicitly identify the drivers of summer streamflow decreases, especially with regard to ET increases.

Nevertheless, the shift of snowmelt to earlier DOYs and a higher rain-snow ratio has been detected also by other studies. With this, the watershed potentially receives more precipitation in the form of rain which in turn possibly leads to higher annual infiltration and interception rates. This water might be additionally available for ET and vegetation growth and thus will reduce seasonal - and hence annual - streamflow amounts. The study of Berghuijs et al. (2014) supports this assumption for the contiguous US: they found observa- 

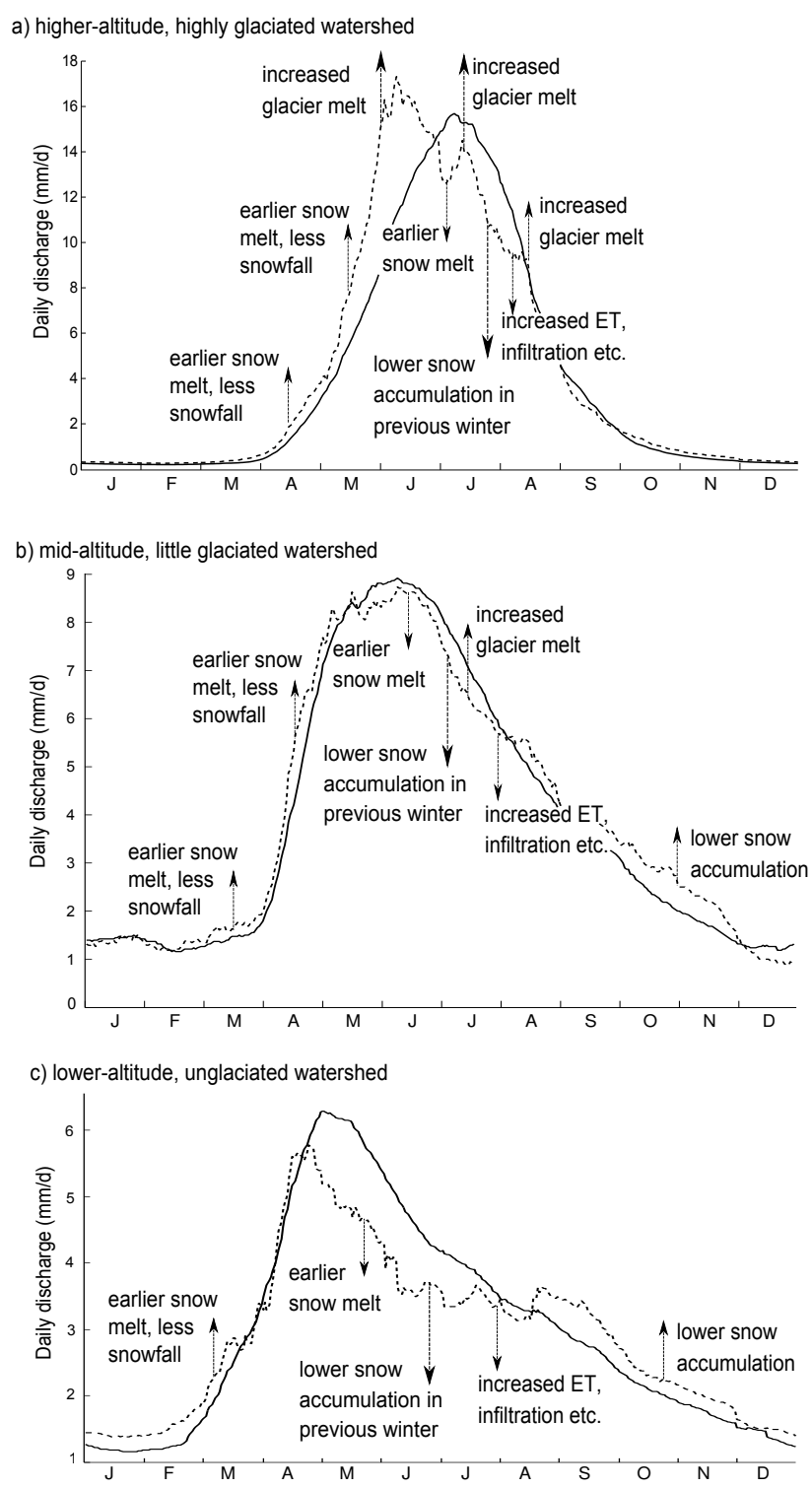

Figure 8. Long-term annual streamflow cycle (1980-2010) of (a) a higher-altitude watershed (Gepatschalm, $2880 \mathrm{~m}, 39.3 \%$ glaciated), (b) a mid-altitude, little glaciated watershed (See i. P., $2303 \mathrm{~m}$, $1.6 \%$ glaciated.) and (c) a lower-altitude, unglaciated watershed (Ehrwald, $1467 \mathrm{~m}$ ), trends generated from the end point of Sen's slope estimator (dashed line, similar to Déry et al., 2009) and potential causes. Long arrows correspond to strong drivers, short arrows to weaker ones.

tional evidence that a reduction in the percentage of snow in total precipitation goes along with decreases in average streamflow.

Also higher transpiration rates through vegetation changes might be (additional) drivers of the summertime streamflow decreases (Jones, 2011): in the study area, alpine livestock farming is the main type of cultivation. The decline of this type of farming during the 1960s and 1970s (Neudorfer et al., 2012) resulted in a still ongoing overgrowth of former grass- lands, enhanced by climate-change related land-use changes such as increases of the timber line (Walther, 2003).

The empirical-statistical model established in the present study was proved to simulate streamflow trends sufficiently well. Not only could it serve as a tool to gain deeper insight into the processes that cause streamflow trends, but it could also be used to derive streamflow trends in alpine catchments where a gauge has been installed only recently. $T$ trends were found to be quite uniform over the entire study region, so a climate station that is very close to the watershed is not absolutely mandatory. The percentage of glaciated areas in the watershed can be derived via glacier cadastres or satellite imagery.

The analysis of hourly streamflow trends supports the findings of the earlier analysis and shows that hourly resolved trend analyses can provide additional information on the changes in alpine streamflow.

\section{Conclusions}

The present study analyses trends and drivers of observed streamflow time series in alpine catchments, taking data from Western Austria as examples. At first, trends of annual averages were analysed: it was found that streamflow at higheraltitude watersheds is generally increasing, while it is decreasing overall in lower-altitude watersheds. The following hypotheses are proposed: (1) positive trends at higher, glaciated watersheds are caused by increased glacial melt, (2) negative trends at lower, non-glaciated watersheds are caused by the hydrological effects of rising temperatures, such as less snowfall causing higher infiltration and in particular increasing ET, and (3) many of the trends at watersheds in mid-altitudes are not identified, because positive and negative trends cancel each other out and the final annual trend is too small to be detected. To support these hypotheses, we attempted to attribute the trends, i.e. we tried to identify the processes that cause the trends.

The biggest challenge in streamflow trend attribution is that streamflow measured at one gauge integrates multiple processes all over the catchment area. This makes the identification of individual drivers difficult, as the final streamflow signal is a result of multiple processes where upward and downward trends could balance each other out. The problem applies for many trend analyses in the literature, where trends are calculated from averages over a certain period of time.

Therefore, trends of filtered daily streamflow data are derived, as they allow for a more precise temporal localization of the trends. The DOYs of these trends are then compared to average DOYs of other hydroclimatological characteristics, such as the temperature surpassing the average freezing point in spring, or, for example, DOYs of trends in snow depth. The DOYs of these long-term characteristics fit well with the ones of the trends found in streamflow time series and thus can be related to them. Additionally, an empirical 
statistical model and analyses of the subdaily changes gave further hints for the causes of the streamflow changes in the study region.

With the present study, we have shown that the hydrological dynamics in alpine areas are changing significantly. Still, looking at the yearly averages of streamflow data, the ongoing change is masked by the fact that additional runoff caused by enhanced glacier melt and possibly increased precipitation is counterbalanced by modifications of the water cycle such as higher ET, less snowfall and rising infiltration in the vegetation season. These opposing forces may balance out within catchments comprising higher and lower altitudes, because the increased streamflow mainly prevails in higher areas while decreasing streamflow is mostly found in lower areas. We are confident that we have identified a rather robust trend of hydrological change in specific hydroclimatological regions, e.g. alpine catchments. Even though the changes are only partially identifiable when one is analysing yearly averages, they can clearly be seen when studying smaller time increments. This detailed analysis of high-resolution hydrological time series follows Merz et al. (2012b), who called for a more rigorous data analysis in order to analyse possible hydrological changes. The identified altered hydrological dynamics in the case of the alpine catchments is driven mostly by temperature increases. This supports Bronstert et al. (2007), who concluded that temperature increases, rather than precipitation changes, cause hydrological changes, which may be quite robustly detectable. A trend attribution of this kind is an important step towards a scientifically sound assessment of climate-change impacts on hydrology. A proceeding step should be the process-based modelling of such hydrological systems (Bronstert et al., 2009), which - if the detected trends can be replicated by the model results - can further sustain the findings concerning climate effects on alpine hydrological systems.
Our attribution approaches could possibly be applied to regions other than mountainous areas. However, one must be aware that results might be rather different and/or less identifiable if changes were not as strongly temperature-driven as those in mountain regions. As stated above, hydrological trend studies should attempt not only to detect but also to attribute the trends. For this reason, it is worth looking for attribution methods adapted to the particular local condition. In any case, daily resolved trends are helpful to detect and attribute hydrological regime changes in alpine catchments, which could be overseen by annual or trimonthly trend assessment. 


\section{Appendix A: The Mann-Kendall test and Sen's slope estimator for trend detection}

The rank-based Mann-Kendall (MK) test was used to calculate the trend significance. The MK test has been widely used in hydrological and climatological analyses (e.g. Gagnon and Gough, 2002; Birsan et al., 2005). Its advantages are its robustness concerning outliers, its high statistical power and the fact that it does not require a certain distribution of the data. A further description of the test is found in Helsel and Hirsch (1992).

The MK test in its original version has two main drawbacks: it accounts neither for autocorrelation in one station data set nor for cross-correlation between data sets of different stations. Both of these could result in the overestimation of an existent trend. Different methods of taking them into account have been published in recent years: concerning serial correlation, the prewhitening method after Wang and Swail (2001) was applied: Lag-1 autocorrelation of the data is first calculated and then removed in the case that it is higher than a certain significance level $(5 \%$ in the present case). To account for spatial correlation in the data, a resampling approach was applied (Livezey and Chen, 1983; Burn and Elnur, 2002): after randomly shuffling the original data set 500 times, all the resampled data sets were tested on trends in the same way as the original one. The percentage of stations that tested significant with a local significance level $\alpha_{\text {local }}$ in the original and in each of the resampled data sets was determined. Based on the distribution of significant trends in the resampled data sets, the value was calculated, which was exceeded with an $\alpha_{\text {field }}=10 \%$ probability. This value was then compared to the percentage of significant results calculated from the original data. In cases where it is higher in the original data set, the patterns found are called "field-significant".
After calculating the significance of a trend, it is necessary to estimate its magnitude, i.e. the slope of the trend. This was done by the robust linear Sen's slope estimator, which is computed from the median of the slope between all possible pairs of data points (Helsel and Hirsch, 1992). The MannKendall trend test and Sen's slope estimator provide complementary information which we combined in illustrating the annual and seasonal trends. However, for reasons of graphical display and continuity we restrict further analyses of the seasonal changes to the Sen's slopes. 

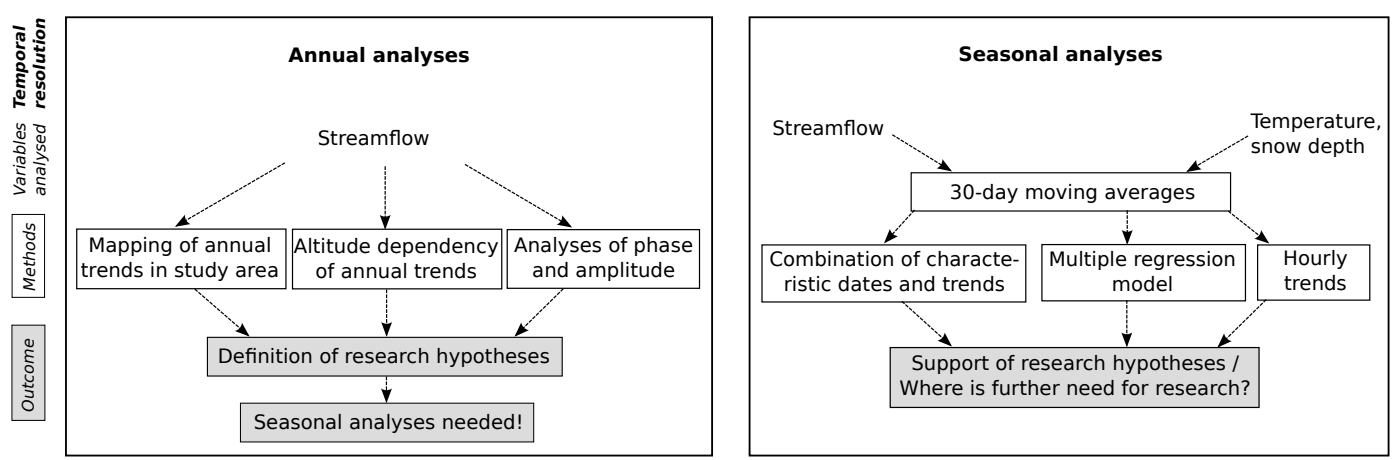

Figure A1. Schematic illustration of the structure of the analyses.

Table A1. List of symbols and abbreviations.

\begin{tabular}{|c|c|c|}
\hline Symbol & Unit & Property \\
\hline$\alpha$ & - & significance level \\
\hline$\alpha_{\text {local }}$ & - & local significance level \\
\hline$\alpha_{\text {field }}$ & - & field significance level \\
\hline$\Delta$ & var. units $\mathrm{yr}^{-1}$ & trend \\
\hline$\Delta Q_{\overline{\text { year }}}$ & $\mathrm{mm} \mathrm{yr}^{-1}$ & trend of annual $Q$ means \\
\hline$\Delta Q_{30 \mathrm{DMA}}$ & $\mathrm{mm} \mathrm{yr}^{-1}$ & trend of 30DMA $Q$ means, for certain DOY at certain station \\
\hline$\overline{\Delta T_{\min }}$ & ${ }^{\circ} \mathrm{C} \mathrm{yr}^{-1}$ & mean trend in $T_{\min }$, averaged over all stations, for certain DOY \\
\hline$\Delta_{\mathrm{MD}}$ & var. units $\mathrm{yr}^{-1}$ & minimal detectable trend \\
\hline$\sigma_{x}$ & variable units & standard deviation \\
\hline 30DMA & variable units & 30-day moving averages \\
\hline$A_{\text {ice }} / A_{\text {tot }}$ & $\%$ & percentage of glaciated area in the watershed \\
\hline DOY & - & day of year \\
\hline$\overline{\mathrm{DOY}}$ & - & characteristic date (average DOY of a certain event) \\
\hline$\overline{\mathrm{DOY}_{0}{ }^{\circ} T_{\text {mean Spring }}}$ & - & average DOY, when $T_{\text {mean }}$ crosses $0^{\circ} \mathrm{C}$ in spring (1980-2010) \\
\hline$\overline{\text { DOY }_{Q_{\max }}}$ & - & average DOY, when annual $Q$ maximum occurs (1980-2010) \\
\hline$\overline{\text { DOY }_{\mathrm{SD}_{\max }}}$ & - & average DOY, when annual SD maximum occurs (1980-2010) \\
\hline ET & $\mathrm{mm}$ & evapotranspiration \\
\hline$Q$ & $\mathrm{~mm}$ & specific runoff \\
\hline$Q_{\overline{\text { year }}}$ & $\mathrm{mm}$ & annual $Q$ mean \\
\hline$Q_{30 \mathrm{DMA}}$ & $\mathrm{mm}$ & 30DMA $Q$ for certain DOY \\
\hline$\overline{Q_{30 \text { DMA }}}$ & $\mathrm{mm}$ & 30DMA $Q$, averaged for $1980-2010$, for certain DOY \\
\hline$\overline{Q_{30 \mathrm{DMA}}}$ & $\mathrm{mm}$ & first derivative of $\overline{Q_{30 \mathrm{DMA}}}$ \\
\hline $\mathrm{SD}$ & $\mathrm{cm}$ & snow depths \\
\hline$S / N$ & - & signal-to-noise ratio \\
\hline$T_{\max }$ & ${ }^{\circ} \mathrm{C}$ & daily maximum temperature \\
\hline$T_{\text {mean }}$ & ${ }^{\circ} \mathrm{C}$ & daily mean temperature \\
\hline$T_{\min }$ & ${ }^{\circ} \mathrm{C}$ & daily minimum temperature \\
\hline$R$ & - & record length \\
\hline
\end{tabular}


Acknowledgements. The authors express their gratitude to Hydrographischer Dienst Tirol (Innsbruck), AlpS GmbH (Innsbruck), Zentralanstalt für Meteorologie und Geodynamik (Vienna), Kommission für Glaziologie (Munich) and Tiroler Wasserkraft AG (Innsbruck) for supplying local station data, and to Efrat Morin (Hebrew University Jerusalem, Israel), Thomas Gräff and Gerd Bürger (University of Potsdam, Germany) for inspiring discussions. We further thank Marius-Victor Birsan, Juraj Parajka and two anonymous reviewers for their work as referees and to Peter Molnar as associate editor. This study was kindly supported by the Potsdam Research Cluster for Georisk Analysis, Environmental Change and Sustainability (PROGRESS) and the Young Scientists Exchange Program (YSEP) in the framework of German-Israeli Cooperation in Water Technology Research, both founded by the German Federal Ministry of Education and Research (BMBF). The YSEP programme was additionally founded by the Ministry of Science, Technology and Space Israel (MOST).

Edited by: P. Molnar

\section{References}

Alaoui, A., Willimann, E., Jasper, K., Felder, G. Herger, F., Magnusson, J., and Weingartner, R.: Modelling the effects of land use and climate changes on hydrology in the Ursern Valley, Switzerland, Hydrol. Process., 28, 3602-3614, doi:10.1002/hyp.9895, 2014.

Auer, I., Böhm, R., Jurkovic, A., Lipa, W., Orlik, A., Potzmann, R., Schöner, W., Ungersböck, M., Matulla, C., Briffa, K., Jones, P. D., Efthymiadis, D., Brunetti, M., Nanni, T., Maugeri, M., Mercalli, L., Mestre, O., Moisselin, J. M., Begert, M., MüllerWestermeier, G., Kveton, V., Bochnicek, O., Stastny, P., Lapin, M., Szalai, S., Szentimrey, T., Cegnar, T., Dolinar, M., GajicCapka, M., Zaninovic, K., Majstorovic, Z., and Nieplova, E.: HISTALP - Historical Instrumental Climatological Surface Time Series of the Greater Alpine Region, Int. J. Climatol., 27, 17-46, 2007

Bard, A., Renard, B., and Lang, M.: The AdaptAlp Dataset. Description, guidance and analyses, Final Report, UR HHLY, Hydrology-Hydraulics, Lyon, 15 pp., 2011.

Barnett, T. P., Adam, J. C., and Lettenmaier, D. P.: Potential impacts of a warming climate on water availability in snow-dominated regions, Nature, 438, 303-309, 2005.

Berghuijs, W. R., Woods, R. A., and Hrachowitz, M. (2014) A precipitation shift from snow towards rain leads to a decrease in streamflow, Nat. Clim. Change, 775, 583-586, doi:10.1038/nclimate2246, 2014.

Birsan, M. V., Molnar, P., Pfaundler, M., and Burlando, P.: Streamflow trends in Switzerland, J. Hydrol., 314, 312-329, doi:10.1016/j.jhydrol.2005.06.008, 2005.

Blöschl, G., Viglione, A., Merz, R., Parajka, J., Salinas, J. L., and Schöner, W.: Auswirkungen des Klimawandels auf Hochwasser und Niederwasser, Österreich. Wasser Abfallwirt., 63, 21-30, 2011.

Burn, D. H. and Elnur, H.: Detection of hydrologic trends and variability, J. Hydrol., 255, 107-122, 2002.

Braun, L. N. and Escher-Vetter, H.: Glacial discharge as affected by climate change, in: vol. 1,Interpraevent Internationales Symposium, Garmisch-Partenkirchen, Germany, 65-74, 1996.
Braun, L. N., Weber, M., and Schulz, M.: Consequences of climate change for runoff from Alpine regions, Ann. Glaciol., 31, 19-25, 2000.

Bronstert, A., Kolokotronis, V., Schwandt, D., and Straub, H.: Comparison and evaluation of regional climate scenarios for hydrological impact analysis: general scheme and application example, Int. J. Climatol., 27, 1579-1594, 2007.

Bronstert, A., Kneis, D., and Bogena, H.: Interaktionen und Rückkopplungen beim hydrologischen Wandel: Relevanz und Möglichkeiten der Modellierung, Hydrol. Wasserbewirt., 53, 289-304, 2009.

Brunetti, M., Lentini, G., Maugeri, M., Nanni, T., Auer, I., Böhm, R., and Schöner, W.: Climate variability and change in the Greater Alpine Region over the last two centuries based on multi-variable analysis, Int. J. Climatol., 29, 2197-2225, doi:10.1002/joc.1857, 2009.

Cahynová, M. and Huth, R.: Changes of atmospheric circulation in central Europe and their influence on climatic trends in the Czech Republic, Theor. Appl. Climatol., 96, 57-68, doi:10.1007/s00704-008-0097-2, 2009.

Calcagno, V. and de Mazancourt, C.: glmulti an R package for easy automated model selection with (generalized) linear models, J Stat. Softw., 34, 1-29, 2010.

Dai, A., Qian, T., Trenberth, K., and Milliman, J.: Changes in Continental Freshwater Discharge from 1948 to 2004, J. Climate, 22 2773-2792, doi:10.1175/2008JCLI2592.1, 2009.

Déry, S. J., Stieglitz, M., McKenna, E. C., and Wood, E. F.: Characteristics and trends of river discharge into Hudson, James, and Ungava Bays, 1964-2000, J. Climate, 18, 2540-2557, 2005.

Déry, S. J., Stahl, K., Moore, R. D., Whitfield, P. H., Menounos, B., and Burford, J. E.: Detection of runoff timing changes in pluvial, nival, and glacial rivers of western Canada, Water Resour. Res., 45, W04426, doi:10.1029/2008WR006975, 2009.

Escher-Vetter, H., Braun, L., and Siebers, M.: Hydrological and meteorological records from the Vernagtferner Basin - Vernagtbach station, for the years 2002 to 2012, doi:10.1594/PANGAEA.829530, 2014.

Gagnon, A. S. and Gough, W. A.: Hydroclimatic trends in the Hudson bay region, Canada, Can. Water Resour. J., 27, 245-262, doi:10.4296/cwrj2703245, 2002.

Garvelmann, J., Pohl, S., and Weiler, M.: Spatio-temporal controls of snowmelt and runoff generation during rain-on-snow events in a mid-latitude mountain catchment, Hydrol. Process., doi:10.1002/hyp.10460, in press, 2015.

Hall, A., Qu, X., and Neelin, J. D.: Improving predictions of summer climate change in the United States, Geophys. Res. Lett., 35, L01702, doi:10.1029/2007GL032012, 2008.

Hall, J., Arheimer, B., Borga, M., Brázdil, R., Claps, P., Kiss, A., Kjeldsen, T. R., Kriaučiūnienè, J., Kundzewicz, Z. W., Lang, M., Llasat, M. C., Macdonald, N., McIntyre, N., Mediero, L., Merz, B., Merz, R., Molnar, P., Montanari, A., Neuhold, C., Parajka, J., Perdigão, R. A. P., Plavcová, L., Rogger, M., Salinas, J. L., Sauquet, E., Schär, C., Szolgay, J., Viglione, A., and Blöschl, G.: Understanding flood regime changes in Europe: a state-of-the-art assessment, Hydrol. Earth Syst. Sci., 18, 27352772, doi:10.5194/hess-18-2735-2014, 2014.

Helsel, D. R. and Hirsch, R. M.: Statistical Methods in Water Resources, Elsevier Science, Amsterdam, 1992. 
Jones, J. A.: Hydrologic responses to climate change: considering geographic context and alternative hypotheses, Hydrol. Process., 25, 1996-2000, 2011.

Kim, J.-S. and Jain, S.: High-resolution streamflow trend analysis applicable to annual decision calendars: A western United States case study, Climatic Change, 102, 699-707, 2010.

Knowles, N., Dettinger, M. D., and Cayan, D. R.: Trends in snowfall versus rainfall in the Western United States, J. Climate, 19, 45454559, 2006.

Kormann, C., Francke, T., and Bronstert, A.: Detection of regional climate change effects on alpine hydrology by daily resolution trend analysis in Tyrol, Austria, J. Water Clim. Change, doi:10.2166/wcc.2014.099, in press, 2014.

Kundzewicz, Z. W.: Searching for changes in hydrological data, Hydrolog. Sci. J., 49, 3-6, 2004.

Livezey, R. E. and Chen, W. Y.: Statistical Field Significance and its Determination by Monte Carlo Techniques, Mon. Weather Rev., 111, 46-59, doi:10.1175/15200493(1983)111<0046:SFSAID>2.0.CO;2, 1983.

Lundquist, J. D., Cayan, D. R., and Dettinger, D. M.: Spring Onset in the Sierra Nevada: When Is Snowmelt Independent of Elevation?, J. Hydrometeorol., 5, 327-342, 2004.

Magnusson, J., Jonas, T., Lopéz-Moreno, I., and Lehning, M.: Snow cover response to climate change in a high alpine and halfglacierized basin in Switzerland, Hydrol. Res., 41, 230-240, 2010.

Merz, B., Maurer, T., and Kaiser, K.: Wie gut können wir vergangene und zukünftige Veränderungen des Wasserhaushalts quantifizieren?, Hydrol. Wasserbewirt., 56, 244-256, doi:10.5675/HyWa_2012,5_1, 2012a.

Merz, B., Vorogushyn, S., Uhlemann, S., Delgado, J., and Hundecha, Y.: HESS Opinions "More efforts and scientific rigour are needed to attribute trends in flood time series", Hydrol. Earth Syst. Sci., 16, 1379-1387, doi:10.5194/hess-16-13792012, 2012b.

Morin, E.: To know what we cannot know: Global mapping of minimal detectable absolute trends in annual precipitation, Water Resour. Res., 47, W07505, doi:10.1029/2010WR009798, 2011.

Mote, P. W., Hamlet, A. F., Clark, M. P., and Lettenmaier, D. P.: Declining mountain snowpack in Western North America, B. Am. Meteorol. Soc., 86, 1-39, doi:10.1175/BAMS-86-1-39, 2005.

Nemec J., Gruber, G., Chimani, B., and Auer, I.: Trends in extreme temperature indices in Austria based on a new homogenized dataset, Int. J. Climatol., 33, 1538-1550, doi:10.1002/joc.3532, 2012.

Neudorfer, T., Pinter, M., Kimer, L., Wendter, S., and Messner, W.: Milchwirtschaft auf Österreichs Almen - Entwicklungen und wirtschaftliche Perspektiven, BMLFUW, Vienna, 2012.

Parajka, J., Kohnová, S., Merz, R., Szolgay, J., Hlavčová, K., and Blöschl, G.: Comparative analysis of the seasonality of hydrological characteristics in Slovakia and Austria, Hydrolog. Sci. J., 54, 456-473, doi:10.1623/hysj.54.3.456, 2009.

Parajka, J., Kohnová, S., Bálint, G., Barbuc, M., Borga, M., Claps, P., Cheval, S., Dumitrescu, A., Gaume, E., Hlavčová, K., Merz, R., Pfaundler, M., Stancalie, G., Szolgay, J., and Blöschl, G.: Seasonal characteristics of flood regimes across the AlpineCarpathian range, J. Hydrol., 394, 78-89, 2010.

Parry, M. L., Canziani, O. F., Palutikof, J. P., van der Linden, P. J., and Hanson, C. E. (Ed.): Climate Change 2007: Impacts, Adap- tation and Vulnerability, in: Contribution of Working Group II to the Fourth Assessment Report of the Intergovernmental Panel on Climate Change, Cambridge University Press, Cambridge, 2007.

Paterson, W. S. B.: The physics of glaciers, 3rd Edn., Pergamon Press, Oxford, 480 pp., 1994.

Pekarova, P., Miklanek, P., and Pekar, J.: Long-term trends and runoff fluctuations of European rivers, in: Climate Variability and Change - Hydrological Impacts, IAHS, UK, 520-525, 2006.

Pellicciotti, F., Bauder, A., and Parola, M.: Effect of glaciers on streamflow trends in the Swiss Alps, Water Resour. Res., 46, W10522, doi:10.1029/2009WR009039, 2010.

Reece, B. and Aguado, E.: Accumulation and melt characteristics of northeastern Sierra Nevada snowpacks, Proc. AWRA 28th Annual Conf. and Symp.: Managing Water Resources during Global Change, AWRA, Reno, NV, 631-640, 1992.

Renner, M. and Bernhofer, C.: Long term variability of the annual hydrological regime and sensitivity to temperature phase shifts in Saxony/Germany, Hydrol. Earth Syst. Sci., 15, 1819-1833, doi:10.5194/hess-15-1819-2011, 2011.

Scherrer, S. C., Appenzeller, C., and Laternser, M.: Trends in Swiss Alpine snow days: The role of local- and largescale climate variability, Geophys. Res. Lett., 31, L13215, doi:10.1029/2004GL020255, 2004.

Schimon, W., Schöner, W., Böhm, R., Haslinger, K., Blöschl, G., Merz, R., Blaschke, A. P., Viglione, A., Parajka, J., Kroiß, H., Kreuzinger, N., and Hörhan, T.: Anpassungsstrategien an den Klimawandel für Österreichs Wasserwirtschaft, Bundesministerium für Land- und Forstwirtschaft, Umwelt und Wasserwirtschaft, Vienna, Austria, 2011.

Stahl, K. and Moore, R. D.: Influence of watershed glacier coverage on summer streamflow in British Columbia, Canada, Water Resour. Res., 42, W06201, doi:10.1029/2006WR005022, 2006.

Stahl, K., Hisdal, H., Hannaford, J., Tallaksen, L. M., van Lanen, H. A. J., Sauquet, E., Demuth, S., Fendekova, M., and Jódar, J.: Streamflow trends in Europe: evidence from a dataset of nearnatural catchments, Hydrol. Earth Syst. Sci., 14, 2367-2382, doi:10.5194/hess-14-2367-2010, 2010.

Stewart, I., Cayan, D., and Dettinger, M.: Changes toward earlier streamflow timing across western North America, J. Climate, 18, 1136-1155, 2005.

Stine, A., Huybers, P., and Fung, I.: Changes in the phase of the annual cycle of surface temperature, Nature, 457, 435-440, 2009.

Tecklenburg, C., Francke, T., Kormann, C., and Bronstert, A.: Modeling of water balance response to an extreme future scenario in the Ötztal catchment, Austria, Adv. Geosci., 32, 63-68, doi:10.5194/adgeo-32-63-2012, 2012.

Viviroli, D., Archer, D. R., Buytaert, W., Fowler, H. J., Greenwood, G. B., Hamlet, A. F., Huang, Y., Koboltschnig, G., Litaor, M. I., López-Moreno, J. I., Lorentz, S., Schädler, B., Schreier, H., Schwaiger, K., Vuille, M., and Woods, R.: Climate change and mountain water resources: overview and recommendations for research, management and policy, Hydrol. Earth Syst. Sci., 15, 471-504, doi:10.5194/hess-15-471-2011, 2011.

Vormoor, K., Lawrence, D., Heistermann, M., and Bronstert, A.: Climate change impacts on the seasonality and generation processes of floods - projections and uncertainties for catchments with mixed snowmelt/rainfall regimes, Hydrol. Earth Syst. Sci., 19, 913-931, doi:10.5194/hess-19-913-2015, 2015. 
Walter, M. T., Wilks, D. S., Parlange, J., and Schneider, R. L.: Increasing evapotranspiration from the conterminous United States, J. Hydrometeorol., 5, 406-408, 2004.

Walther, G.-R.: Plants in a warmer world, Perspect. Plant Ecol. Evol. Syst., 6, 169-185, 2003.

Wang, X. L. L. and Swail, V. R.: Changes of extreme wave heights in Northern Hemisphere oceans and related atmospheric circulation regimes, J. Climate, 14, 2204-2221, doi:10.1175/15200442(2001)014<2204:COEWHI>2.0.CO;2, 2001.
Weber, M., Prasch, M., Kuhn, M., Lambrecht, A., and Hagg, W. Ice reserves - sub-project glaciology, Chapter 1.8, GLOWADanube-Project, Global Change Atlas, LMU Munich, Munich, 2009.

Whitfield, P. H.: Is 'Centre of Volume' a robust indicator of changes in snowmelt timing?, Hydrol. Process., 27, 2691-2698, doi:10.1002/hyp.9817, 2013. 